BNL -67588

\title{
MICROANALYSIS OF MATERIALS USING SYNCHROTRON RADIATION
}

\author{
Keith W. Jones and Huan Feng \\ Brookhaven National Laboratory
}

Upton, New York 11973

\begin{abstract}
To be Published in
Chemical Applications of Synchrotron Radiation

Edited by

T. K. Sham

World Scientific Publishing Company, New Jersey
\end{abstract}

2000

By acceptance of this article, the publisher and/or recipient acknowledges the US Government's right to retain a nonexclusive, royalty-free license in and to any copyright covering this paper. 
COVER SHEET

\section{CHEMICAL APPLICATION OF SYNCHROTRON RADIATION}

(Complete form and attach to front of the original manuscript)

Title of Paper: Microanalysis of Materials Using Synchrotron Radiation

Name of Authors (in same sequence as listed on title page):

Keith W. Jones and Huan Feng

\section{Corresponding Author}

Full Name: Keith W. Jones

Full Address:

Building 901A

Brookhaven National Laboratory

Post Office Box 5000

Upton, NY 11973-5000 USA

Telephone Number: $631-344-4588$

Fax Number: 631-344-5271

e-Mail: kwj@bnl.gov

Keyword for Paper (maximum of six):

Synchrotron radiation, $\mathrm{x}$-ray fluorescence, diffraction, tomography 
Microanalysis of Materials Using Synchrotron Radiation

Keith W. Jones and Huan Feng

Building 901A

Brookhaven National Laboratory

Post Office Box 5000

Upton, New York 11973-5000 


\section{Table of Contents}

1 Introduction

$2 \quad$ Basic Approaches

2.1 Synchrotron x-ray production

$2.2 \quad \mathrm{X}$-ray cross sections

2.3 Synchrotron-radiation-induced x-ray emission (SRIXE)

2.4 Extended x-ray absorption fine structure (EXAFS) and extended x-ray absorption nearedge structure (XANES)

2.5 Computed microtomography (CMT)

2.6 Sample radiation damage effects

3 Applications

3.1 Biological applications

3.1.1 Reversible effect of low lead levels on neuronal growth

3.1.2 Analysis of zinc binding capabilities of a protein domain

3.1.3 Stroke and calcium concentrations in the brain

3.1.4 Studies of bone and cartilage

3.2 Geological and extraterrestrial materials

3.2.1 Microstructure of shocked-recovered Berea sandstone

3.2.2 Internal structure of two type-I deep-sea spheres by x-ray computed microtomography

3.2.3 Hydrothermal vents

3.2.4 Investigation of New York/New Jersey Harbor dredged material 


\subsection{Environmental chemistry}

3.3.1 Secondary ion mass spectroscopy and synchrotron $\mathrm{x}$-ray fluorescence in the study of the qualitative variation in metal content with time in tree rings

3.4 Materials analysis

\subsubsection{Thermal spray}

\subsubsection{Study of supported catalysts}

3.4.3 Investigation of integrated circuit structures using CMT and microdiffraction

$4 \quad$ Summary

5 Acknowledgements

$6 \quad$ References

$7 \quad$ Table

$8 \quad$ Figure captions

$9 \quad$ Figures 


\section{Introduction}

High intensity synchrotron radiation produces photons with wavelengths that extend from the infrared to hard $\mathrm{x}$ rays with energies of hundreds of $\mathrm{keV}$ with uniquely high photon intensities that can be used to determine the composition and properties of materials using a variety of techniques. Most of these techniques represent extensions of earlier work performed with ordinary tube-type $\mathrm{x}$-ray sources. The properties of the synchrotron source such as the continuous range of energy, high degree of photon polarization, pulsed beams, and photon flux many orders of magnitude higher than from $\mathrm{x}$-ray tubes have made possible major advances in the possible chemical applications.

We describe here ways that materials analyses can be made using the high intensity beams for measurements with small beam sizes and/or high detection sensitivity. The relevant characteristics of synchrotron $\mathrm{x}$-ray sources are briefly summarized to give an idea of the $\mathrm{x}$-ray parameters to be exploited. The experimental techniques considered include x-ray fluorescence, absorption, and diffraction. Examples of typical experimental apparatus used in these experiments are considered together with descriptions of actual applications.

A number of similar reviews have been published in the past. A comprehensive survey of the overall field of synchrotron research was given in a book edited by Winick and Doniach ${ }^{1}$ about 20 years ago. Obviously, there have been massive changes in this rapidly growing field since that time; nevertheless, the different chapters in this collection remain a very valuable introductory survey covering the basics of the production and use of synchrotron radiation. Recent reviews have been given that are more specialized and are thus perhaps more relevant to the topics considered here ${ }^{2-10}$. 
In considering applications that are appropriate for consideration in this survey, we had recourse to a dictionary definition of chemistry: "the science dealing with the composition and properties of substances, and with the reactions by which substances are produced from or converted into other substances." ${ }^{11}$ The application of $\mathrm{x}$-ray microbeams or other imaging technologies that measure elemental composition or structure will fit this very broad definition. Thus, we have felt free to discuss topics that might reasonably be included in materials sciences, earth and planetary sciences, biomedical sciences, and environmental science--if a very specialized view is taken.

Our main emphasis will be on the use of high-energy $(>1 \mathrm{keV}) \mathrm{x}$ rays that can be used to investigate elemental compositions with excellent spatial resolutions and low detection limits using two techniques. One technique uses synchrotron radiation-induced $\mathrm{x}$-ray emission (SRIXE). This acronym is chosen in preference to the acronym $\mathrm{x}$-ray fluorescence (XRF) to emphasize relationship with the analogous particle induced $\mathrm{x}$-ray emission (PIXE) technique. The other technique is that of computed microtomography (CMT) which is based primarily on the measurement of the absorption of the x-ray beam in a sample. CMT gives a means of noninvasively measuring a volume in the sample and determining the varying composition in a heterogeneous material.

There is now a large literature describing experiments based on the techniques of SRIXE and CMT. We have emphasized work done at the Brookhaven National Laboratory (BNL) National Synchrotron Light Source (NSLS), but have also included descriptions of work done at other synchrotron laboratories around the world. This is a very selective description of the field, and no effort was made to produce a complete bibliography that covered all experiments performed. 


\section{Basic Approaches}

\subsection{Synchrotron $x$-ray production}

The synchrotron x-ray source has been developed over the course of many years. Various stages of development have been described as Generations 1,2,3, and 4. At present, we are in an era when both Generation 2 and Generation 3 facilities are in operation and development work for Generation 4 facilities is in progress. From the standpoint of the facility user, it is not necessary to have a very detailed knowledge of the operation of a synchrotron. Rather, the important need is to define the beams supplied to the end user. The beams are produced as the electron beam in the synchrotron passes through a bending magnet used to contain the circulating beam or through undulator or wiggler insertion devices which can be used to increase the beam intensity or shift the energy to higher values. A very broad definition of the difference between the second- and third-generation $\mathrm{x}$-ray sources is that the third-generation source has been engineered to maximize the use of insertion devices.

The major parameters are the brilliance, brightness, and flux given as a function of photon energy where the brilliance gives the number of photons emitted per unit source area per second per unit solid angle, the brightness is the number of photons emitted into a given solid angle integrated over the source area, and the flux is the number of photons per second per horizontal opening angle. For the NSLS the source area is about $565 \mathrm{~mm} \times 49 \mu \mathrm{m}$, or less, in the $\mathrm{x}$ - and $\mathrm{y}$-directions, respectively. The energy bandwidth is taken to be $0.1 \%$ for all three cases. The performance of a bending magnet at the NSLS is shown in Figure 2.1-1 for a stored electron beam current of $500 \mathrm{~mA}$, the NSLS design value. 
The source distance for the $\mathrm{x}$-ray microprobe located on the NSLS X26A beam line is 10 $\mathrm{m}$. The $\mathrm{x}$ rays passing through a $1 \mu \mathrm{m} \times 1 \mu \mathrm{m}$ aperture can then be estimated as about $6 \times 10^{5}$ $10-\mathrm{keV}$ photons $/ \mathrm{s} / 0.1 \%$ bandwidth at $500 \mathrm{~mA}$ by reference to Figure $2.1-1 \mathrm{~b}$. An increase in beam intensity can be achieved by either increasing the bandwidth or using a focusing device to reduce the size of a beam that has been defined by a larger aperture.

\subsection{X-ray cross sections}

A knowledge of cross sections for the interaction of $\mathrm{x}$-ray beams with matter is often useful in designing synchrotron experiments and for the interpretation of experimental results. A convenient compendium of relevant information is provided by the National Institute of Standards and Technology ${ }^{12}$.

\subsection{Synchrotron-radiation-induced x-ray emission (SRIXE)}

SRIXE is used to determine elemental concentrations through the detection of characteristic $\mathrm{x}$ rays produced by the interaction of the synchrotron $\mathrm{x}$-ray beams with a sample material. The main concern from an experimental standpoint is to balance the need for high spatial resolution for the analysis of heterogeneous materials with the conflicting requirement for obtaining the best possible detection limits.

The SRIXE apparatus consists of basically four components: first, monochromators, collimators and focusing lenses for producing a microbeam; second, a computer-controlled sample stage for point-by-point mapping the elemental spatial distributions; third, a suitable $\mathrm{x}$ ray detection system such as a lithium-drifted silicon $\mathrm{x}$-ray detector. 
The simplest approach to the solution of this problem is to rely on a pinhole collimator for production of a microbeam. We can easily make a rough estimate of the number of characteristic $\mathrm{x}$ rays produced. Assume that a $1 \mu \mathrm{m} \times 1 \mu \mathrm{m}$ beam irradiates $1 \mathrm{fg}$ of $\mathrm{Fe}\left(1.08 \times 10^{7}\right.$ atoms) with $6 \times 10^{5} 10-\mathrm{keV}$ photons/s (see above) and the fluorescent Fe K-x rays are detected with a $30-\mathrm{mm}^{2} \mathrm{Si}(\mathrm{Li})$ detector placed $4 \mathrm{~cm}$ from the sample at 90 degrees to the incident beam. The detector counting rate for the Fe-x rays is then 20 counts per second. A white beam can be used to eliminate the need for the monochromator and to maximize the number of available photons. The presence of a background of scattered photons will, of course, affect the minimum detection limits that can be achieved. This approach has been used at the NSLS for a number of years with great success ${ }^{2}$ and does show that detection limits around $1 \mathrm{fg}$ can be reached.

The addition of a monochromator for production of a monoenergetic beam is desirable, but results in a concomitant reduction in the photon flux. This then necessitates the use of a compensating focussing element to increase the photon flux at the sample. A discussion and summary of the different focusing methods that have been employed has been given recently by Hayakawa and Gohshi ${ }^{?}$.

One of the commonly-used devices was developed many years ago by Kirkpatrick and $\mathrm{Baez}^{13}$. An initial demonstration experiment using the Kirkpatrick-Baez (KB) mirror system was carried out at the NSLS by a team from Lawrence Berkeley National Laboratory, University of Chicago, and $\mathrm{BNL}^{14}$. The results showed that it was possible to achieve excellent spatial resolution, approximately $10 \mu \mathrm{m} \times 10 \mu \mathrm{m}$, and minimum detection limits as low as $2 \mathrm{fg}$ on a bending magnet source at a beam energy of $10 \mathrm{keV}$ and a band-pass of $1 \mathrm{keV}$. The photon flux was about $3 \times 10^{7}$ photons $/ \mathrm{s}$ at a source distance of $20 \mathrm{~m}$ and a $0.5 \mathrm{~mm} \times 0.5 \mathrm{~mm}$ object size. The detection limits obtained under these conditions are shown in Table 1. 
A similar system has been placed in operation by the University of Chicago ${ }^{15}$ on another NSLS bending magnet beam line with an experimental station at $10 \mathrm{~m}$ from the source position. The KB mirrors in this case are designed to work in conjunction with monoenergetic $\mathrm{x}$ rays produced by a Si monochromator. They have a heavy metal coating to enhance the reflectivity for high-energy $\mathrm{x}$ rays. A schematic diagram of the beam line is shown in photograph of the apparatus is given in Figure 2.3-1. A photograph of the apparatus is given in Figure 2.3-2. The spatial resolution of the system is typically $10-15 \mu \mathrm{m}$ obtained with an object size of $350 \mu \mathrm{m}$. The $\mathrm{x}$-ray flux is about $10^{9}$ photons $/ \mathrm{s} / \mu \mathrm{m}^{2} / 0.1 \%$ bandwidth.

Typical X-ray spectra measured with the KB system for National Bureau of Standards Standard Reference Materials (SRMs) 1832 and 1833 are shown in Figure 2.3-3. These standards are glass films $0.55 \mu \mathrm{m}$ thick with known trace-element concentrations. SRM 1832 contains $\mathrm{Na}, \mathrm{Al}, \mathrm{Si}, \mathrm{Ca}, \mathrm{V}, \mathrm{Mn}, \mathrm{Co}$, and $\mathrm{Cu}$. SRM 1833 contains $\mathrm{Si}, \mathrm{K}, \mathrm{Ti}, \mathrm{Fe}, \mathrm{Zn}$, and $\mathrm{Pb}$. The spectra were obtained using a beam energy of $16.95 \mathrm{keV}$ and an acquisition time of 15 minutes. As an example, estimated minimum detection limits are 1-10 ppm.

The Chicago group has recently reported on a similar system now in operation at the Argonne Advanced Photon Source (APS). There it was possible to take advantage of an undulator source to produce $\mathrm{x}$-ray fluxes which are not only much higher than those from the NSLS bending magnets but which also cover a much broader energy range. This makes feasible the measurement of rare earth elements using $\mathrm{K}$-x rays thereby eliminating interference from transition element $\mathrm{K}-\mathrm{x}$ rays found when it is necessary to use L-x rays. A photograph of the APS system is shown in Figure 2.3-4. The x-ray detection efficiency is also enhanced by use of a 13element $\mathrm{Ge}$ detector system. The object size for the $\mathrm{KB}$ mirror system is $350 \mu \mathrm{m} \times 350 \mu \mathrm{m}$. A measurement of the spatial resolution obtained, about $0.8 \mu \mathrm{m}$, is shown in Figure 2.3-5. The 
photon flux of the APS system is $10^{12}$ photons $/ \mathrm{s} / \mu \mathrm{m}^{2} / 0.1 \%$ bandwidth with a minimum detection limit of about $10 \mathrm{ag}$. Thus, there is an improvement over the NSLS instrumentation of about a factor of a thousand for minimum detection limits and a factor of 10 to 20 for the spatial resolution.

The use of tapered capillary focusing is another approach that has been developed by several groups. Bilderback et al ${ }^{16}$ showed that it was possible to obtain spatial resolutions of about $0.1 \mu \mathrm{m}$. Riekel et al. ${ }^{17}$ working at the European Synchrotron Research Facility (ESRF) and Cargill and Noyan et al. ${ }^{18}$ working at the NSLS have both produced x-ray microprobes based on capillary focussing and applied them to microdiffraction experiments. The Riekel group used an undulator source, Si monochromator, and a tapered capillary which reduced the beam size to about $2 \mu \mathrm{m}$. The photon flux was about $2 \times 10^{10}$ photons $/ \mathrm{s} / \mu \mathrm{m}^{2}$ for a photon energy of $13 \mathrm{keV}$.

\subsection{Extended x-ray absorption fine structure (EXAFS) and extended x-ray absorption near-edge structure (XANES)}

Extended x-ray absorption fine structure (EXAFS) and extended x-ray absorption nearedge structure (XANES) experiments are well known techniques for measuring the redox state of elements and determining their nearest neighbors in chemical compounds. The basis of these methods have been presented by Brown and Doniach ${ }^{19}, \operatorname{Brown}^{20}$, Lytle, Via, and Sinfelt ${ }^{21}$, Doniach, Eisenberger, and Hodgson ${ }^{22}$, Koningsberger and Prins ${ }^{23}$, and Fendorf $\mathrm{f}^{24}$.

\subsection{Computed microtomography (CMT)}

Computed microtomography (CMT) is a non-destructive technique which can be used to determine the microstructure of materials with best spatial resolutions of the order of $1 \mu \mathrm{m}$. The 
structures can be defined in terms of either the x-ray absorption coefficients or in terms of elemental concentrations. The techniques have been intensively developed for many years for application in medical diagnostics and for industrial applications. High intensity synchrotron xray beams have made it possible to extend the applicability to voxel sizes in the $1 \mu \mathrm{m}^{3}$ range and simultaneously maintain reasonable data acquisition times.

Early work in the field was carried out by several groups. Spanne and Rivers ${ }^{25}$ described a first-generation apparatus that was based on a pencil x-ray beam formed by a collimator. Data were then obtained by scanning the beam across the sample combined with measurements at different sample angles with respect to the beam at each position. D'Amico et al. ${ }^{26}$, Flannery et al. ${ }^{27}$, Bonse et al. ${ }^{28}$, and Kinney et al. ${ }^{29}$ used a third-generation apparatus that eliminated the need for translation of the sample through the beam by use of an area detector which recorded the transmission of a beam that covered the entire sample.

More recently, a third-generation apparatus was put into operation at the NSLS by Dowd et al. ${ }^{30,31}$ A schematic diagram of the apparatus is shown in Figure 2.5-1 and a photograph of the apparatus in Figure 2.5-2. The $\mathrm{x}$ rays are detected with a thin scintillator of CsI(Na) or YAG:Ce. A mirror/lens system is used to focus light from the scintillator on the CCD camera. Blurring effects caused by scattering of the $\mathrm{x}$ rays in the scintillator are minimized by the small depth-offield of the magnifying lens. The spatial resolution of the system is estimated at $1.7 \mu \mathrm{m}$. The CCD cameras used employed CCD chips with $1317 \times 1035$ and $3072 \times 2048$ pixels. In practice, the pixels are often binned to reduce the size of the tomographic volumes and thereby ensure practicable times for data acquisition and reconstruction. A monochromator can be used to select $\mathrm{x}$-ray energies from 5.5 to $36 \mathrm{keV}$. Filtered white beam can be used to obtain higher $\mathrm{x}$-ray 
intensities and to make measurements at higher energies. The total time for these two steps is about 1 hour for a $256^{3}$ volume.

\subsection{Sample radiation damage effects}

The passage of x-ray, electrons, or heavy charged particles through a material causes changes in the material via energy loss mechanisms mainly related to the interaction of the particles with electrons in the solid. The damage caused by photons has been observed to occur even at the relatively low fluences that have been provided by bending magnet sources at secondgeneration synchrotron facilities. Using the undulator sources at third-generation facilities gives beam fluences similar to those reached with conventional electron probes.

Themner et al..$^{32}$ studied mass loss for $10-12 \mathrm{keV}$ photons using a white beam from a bending magnet at the NSLS. The energy spectrum of $\mathrm{x}$ rays produced in the 90 -degree scattering of the white beam from a 3.5- $\mathrm{m}$ polyester film is shown in Figure 2.6-1. The number of scattered $\mathrm{x}$ rays in the energy region from 10 to $12 \mathrm{keV}$ was taken to be proportional to the mass of the sample. Comparison of the intensity of the scattered radiation before and after a long irradiation showed that there was a mass loss of about $20 \%$ for a 29 -minute irradiation The x-ray dose was $10^{8} \mathrm{~Gy}$. On the other hand, irradiation of a polyimide film produced no mass loss with a 29-minute exposure. Results obtained from the irradiation of a skin specimen, taken as an example of a biological specimen, are shown in Figure 2.6-2. The x-ray doses ranged up to $60 \times 10^{6} \mathrm{~Gy}$. In this case a reduction in the scattered x-ray intensity was observed that corresponded to a mass loss of about $25 \%$.

In an earlier experiment Slatkin et al., ${ }^{33}$ also using a white beam from a NSLS bending magnet, investigated morphological changes in human blood cells. Significant signs of damage 
were found after exposure to $10^{11}$ photons $/ \mu \mathrm{m}^{2}$. This value is similar to the value of $8 \times 10^{10}$ photon fluence estimated for the case of the skin irradiation.

Mass loss or morphological change are probably somewhat crude measures of the damage caused by the synchrotron beam. Diffraction experiments are well known to be affected by radiation-induced changes in the sample structure. Singer et al ${ }^{34}$ examined Laue diffraction patterns of orthorhombic trypsin, tetragonal hen egg-white lysozyme, and hexagonal glutathione synthase on NSLS bending magnet and 25-pole wiggler beam lines. A series of exposures were taken in order to simulate a dynamic experiment. Measurements of trypsin crystals were found to be very radiation resistant and glutathione synthase very radiation sensitive and were found to be damaged in a single exposure of $125 \mathrm{~ms}$ on the wiggler beam line.

In another experiment, a collaboration between ESRF, BNL, and the University of Massachusetts (C. R. Riekel and P. Engstrom, ESRF; K. W. Jones, BNL; and W. C. Connor, Jr., University of Massachusetts) examined the crystallinity of thin sections of polyethylene polymerization particles at the ESRF beam line described above. In this case it was found that crystallinity was destroyed in an irradiation time of about 1 minute.

Taken together, these experiments show that radiation damage effects can be of importance in affecting the results of synchrotron experiments. The amount of damage to a sample will depend on the irradiation conditions and the chemical composition and physical state of the sample. This damage is of importance even at relatively low fluxes from the NSLS and certainly will deserve increased attention at the higher fluxes from the APS, ALS, and other similar storage facilities. 


\section{Applications}

\subsection{Biological applications}

There are many ways that synchrotron radiation is used for study of biological materials. The most prominent example is the application of $\mathrm{x}$-ray diffraction methods for determination of protein structures. This is an extremely active field of research pursued at many synchrotron facilities by scientists from universities, industrial, and government laboratories. The high fluxes and time structure of the $\mathrm{x}$-ray beams from the synchrotrons have been effective in reducing data acquisition times and making kinetic measurements feasible on very small samples. We have chosen to exclude this field from consideration in this review since its scope precludes a reasonable summary in the space available.

We have, instead considered other applications where analysis of small biological samples with synchrotron $\mathrm{x}$-ray beams is a useful experimental approach that complements more traditional methods. The techniques involved are SRIXE and CMT. Applications of SRIXE are given for elemental analysis of tissue samples where the quantity of tissue is not large enough for easy use of atomic absorption spectroscopy or inductively-coupled plasma mass spectrometry and of CMT for determination of the structure of bone and teeth.

\subsubsection{H. T. Cline, S. Witte, and K. W. Jones. Reversible effect of low lead levels on neuronal growth ${ }^{35}$}

Lead is a toxic metal that represents a major public health problem for several reasons. In particular, it affects the development of the brain in children and can cause learning disabilities and behavioral problems that include deficits in visual system function. Questions about lead toxicity include determination of the exposure that causes neurological damage and 
whether or not this damage is reversible. These questions were investigated by considering the development of visual projection in frogs including neuronal growth, synaptic transmission, and the maintenance of topographic retinotectal projections. In addition, an assessment was made of the relative effects of using the chelating agent 2,3 dimercaptosuccinic acid (DMSA) to reverse the effect of lead exposure on neuronal growth as compared to the effect produced by the simple removal of the lead source from the animal.

The tadpoles used in the experiment were exposed to lead contained in a slow release plastic polymer which releases low molecular weight compounds at a constant rate over a long time period. The polymer which contained $5 \mathrm{ng}$ of lead was surgically implanted in the optic tectum of the experimental animals. They were exposed to the lead for 6 weeks and then terminally anesthetized. Sections through the optic tectum $1 \mu \mathrm{m}$ thick were prepared and analyzed for lead and zinc content using the x-ray microscopy apparatus at the NSLS beam line X26 using a white beam with a size on the sample of $8 \mu \mathrm{m} \times 11 \mu \mathrm{m}$. Results obtained for measurements of exposed and control brain sections for a data acquisition time of $5500 \mathrm{~s}$ are shown in Figure 3.1-1. Estimated concentrations were $200 \mathrm{ppb}$ and $100 \mathrm{ppb}$ for the exposed and control samples, respectively. Lead concentrations in pooled whole brain and eye specimens from 8-10 animals were measured using atomic absorption spectroscopy (AAS). It was possible to detect lead only in specimens exposed to $50 \mathrm{ng}$ lead. This demonstrates the effectiveness of SRIXE for measurements of low concentrations in small sample sizes.

Overall, measurements of brain retinal axon arbor morphology, retinotectal topography, and electrophysiology were made to characterize the effects of the lead exposures. The results found from these measurements indicate that the exposure to lead at nanomolar concentrations caused a reduction in growth of retinal ganglion cell axonal projections, but did 
not change the topographic organization of the retinotectal projection. The effects are greater than previously observed at the low lead concentrations used in this experiment. It is argued that development of nervous systems in amphibians and humans relies on similar cellular mechanisms and that, as a consequence, lead-induced cognitive defects in humans could be traced, at least in part, to changes in neuronal growth caused by the exposure. Finally, treatment with DMSA was shown to effectively reverse the effect of lead on neuronal growth whereas removal of the lead source did not. This finding is important since it supports the use of DMSA chelation therapy in children.

\subsubsection{T. Pfister, E. Wimmer, K. W. Jones and H. Feng. Analysis of zinc binding capabilities of a protein domain ${ }^{36,37}$}

Poliovirus is the causative agent of poliomyelitis and is a prototypical member of the Picornaviridae, a family of small, icosahedral viruses containing a single positive-sense RNA molecule that encodes structural and non-structural proteins. The non-structural protein $2 \mathrm{C}$ of poliovirus is an ATPase and contains the motifs characteristic for superfamily 3 helicases.

However, helicase activity has not been found. Protein $2 \mathrm{C}$ has been reported to be involved in RNA replication, virus assembly and rearrangement of the host cell membranes. The molecular mechanisms that underlie the diverse involvement of protein $2 \mathrm{C}$ are not known. In the present study we focused on a cysteine-rich motif near the carboxy terminus of poliovirus protein $2 \mathrm{C}$. Genetic evidence indicated that the cysteine-rich motif is required for a function of $2 \mathrm{C}$ in RNA replication. The sequence of the motif is CKNCHQPANFKRCCPLVC. The arrangement of the cysteine residues resembles that of zinc finger proteins in which one zinc atom is coordinated by four thiol groups. 
SRIXE was used to test for the ability of the cysteine-rich motif to bind zinc. The cysteine-rich motif fused with the carboxy terminus of glutathione S-transferase (GST-CR ${ }^{\mathrm{wt}}$ ) was expressed in Escherichia coli and purified on glutathione-sepharose beads. The eluted protein was applied in solution onto hydrophobic membranes ${ }^{38}$ and the emission spectrum was recorded. GST (GST) and GST fused to the motif of which all cysteine residues were replaced by serine residues (GST-CR ${ }^{\text {mur }}$ ) were used as negative controls. GST fused to the proximal zinc finger motif of the human transcription factor 3A (GST-ZF3A) was used as a positive control. The data indicated that GST alone bound zinc. However, the amount of zinc bound to GST-ZFM and GST-ZF3A was significantly higher than that of GST and GST-ZF4. Quantification of zinc suggested that GST binds one zinc atom by itself and the cysteine-rich motif binds an additional zinc atom. We suggest that SRIXE is a powerful method to detect zinc and other atoms in proteinaceous samples. The high sensitivity of SRIXE and the small protein sample required is especially advantageous when only a small amount of the target protein is available. In combination with the widely used GST expression system, two major advantages became apparent. First, GST fused to small protein domains are usually expressed to large amounts and their easy to purify features are often not observed with full-size proteins. Second, the method not only allows us to address metal binding capabilities of a protein, but, also, metal binding capabilities of a particular domain within a protein. 


\subsubsection{G. C. Newman, S. Trowbridge (Northport VAMC, SUNY/Stony Brook, Department of Neurology, School of Medicine), and K. W. Jones (BNL). Stroke and calcium concentrations in the brain ${ }^{39}$}

There are wide reaching disturbances of $\mathrm{Ca}^{2+}$ metabolism under conditions of ischemia. At ischemia onset, there is depolarization of the tissue with release and accumulation of glutamate and $\mathrm{K}^{+}$in the extracellular space (ECS). Early depolarization results in a rise of free cytoplasmic $\mathrm{Ca}^{2+}$ due to release of $\mathrm{Ca}^{2+}$ from intracellular stores and influx from ECS. As hypoxia limits ATP generation and acidosis results from the anaerobic glycolysis which accelerates in an effort to compensate, $\mathrm{Ca}^{2+}$ cannot be properly sequestered and concentration gradients in the cell gradually disintegrate. As $\mathrm{Ca}^{2+}$ rises toward $5 \mu \mathrm{M}$ in the cytoplasm, the mitochondria develop membrane pores which permit free movement of all molecules less than $1000 \mathrm{MW}$. Eventually, ischemic brain undergoes anoxic depolarization with massive release of $\mathrm{K}^{+}$into the ECS and entry of $\mathrm{Ca}^{2+}$ into the cell.

The present experiment was designed to test the hypothesis that tissue $\mathrm{Ca}^{2+}$ is regulated independent of extracellular $\mathrm{Ca}^{2+}$ concentration. Brain slices isolated from rat hippocampus were incubated in buffers with a range of $\mathrm{Ca}^{2+}$ concentrations from $4.5 \mathrm{mM}$ to $0.001 \mathrm{mM}$. Buffer $\mathrm{Ca}^{2+}$ was labeled with ${ }^{45} \mathrm{Ca}$. A volume of distribution for ${ }^{45} \mathrm{Ca}$ was calculated at each buffer $\mathrm{Ca}^{2+}$, and total tissue $\mathrm{Ca}^{2+}$ can be calculated from that volume. Contrary to expectations, based on the experiments with ${ }^{45} \mathrm{Ca}$, it appears that the volume of distribution remains nearly constant from $4.5 \mathrm{mM}$ to below $0.5 \mathrm{mM}$ so that tissue $\mathrm{Ca}^{2+}$ is directly related to extracellular $\mathrm{Ca}^{2+}$. Even below $0.5 \mathrm{mM}$ external $\mathrm{Ca}^{2+}$, the rise in the volume of distribution is not very great so that the relationship between tissue and buffer $\mathrm{Ca}^{2+}$ remains very nearly linear. In this experiment, it is assumed that 1) all tissue $\mathrm{Ca}^{2+}$ pools are labeled by ${ }^{45} \mathrm{Ca}$ during the one-hour incubation with 
isotope or at least that 2) the fraction of labeled tissue $\mathrm{Ca}^{2+}$ remains constant at all buffer $\mathrm{Ca}^{2+}$. Either or both of these assumptions may be incorrect. There is need, therefore, to measure tissue $\mathrm{Ca}^{2+}$ independently of radiolabeling by exchange equilibrium and thus determine the fraction of tissue $\mathrm{Ca}^{2+}$ which equilibrates as a function of buffer $\mathrm{Ca}^{2+}$.

The approach we chose was to repeat the slice incubations to create the concentration response curve, but without ${ }^{45} \mathrm{Ca}$ in the buffer and to measure tissue $\mathrm{Ca}^{2+} \mathrm{SRIXE}$ which has highspatial resolution combined with excellent minimum detection levels. Measurements were made on $450-\mu \mathrm{m}$ thick sections of rat hippocampus for buffer concentrations from 0 to $4.5 \mathrm{mM}$. The $\mathrm{Ca}$ concentrations were normalized to the tissue $\mathrm{K}$ concentrations to remove uncertainties arising from variations in tissue thickness.

These experiments suggest that the assumption that ${ }^{45} \mathrm{Ca}$ labels either all or a constant fraction of $\mathrm{Ca}^{2+}$ is not valid. Certainly the results suggest that when buffer $\mathrm{Ca}^{2+}$ is below $1 \mathrm{mM}$, a significant portion of the tissue $\mathrm{Ca}^{2+}$ is not labeled by ${ }^{45} \mathrm{Ca}$. A rough estimate of the size of the unlabeled $\mathrm{Ca}^{2+}$ pool is about $0.1 \mathrm{mM}$. Questions surrounding the ${ }^{45} \mathrm{Ca}$ measurements take on greater significance in light of our recent finding that, in brain slices, ischemic injury is accompanied by irreversible uptake of ${ }^{45} \mathrm{Ca}$ in a tissue compartment. The nature of the compartment may hold an important clue for how $\mathrm{Ca}^{2+}$ contributes to irreversible tissue injury in ischemia.

\subsubsection{Studies of bone and cartilage}

Measurements of the elemental composition of bone and cartilage are important for achieving better understanding of age-related changes in structure and chemistry and for understanding the fate and transport of toxic elements such as lead or elements used for 
therapeutic purposes. A number of related studies have been carried out at the BNL X26 beam line to investigate these points.

Yasamura et al.$^{40}$ used CMT, SRIXE, photon and neutron activation analysis, and whole body counting of ${ }^{40} \mathrm{~K}$ to investigate changes in the femur of rats aged 6,12 , and 24 months. The results showed that there were changes in both the bone morphology and regional chemical composition as a function of age. It was also pointed out that the use of CMT for structure determinations could be applied in vivo so that longitudinal studies could be carried out for studies of effects of treatment for disease or other reasons.

Bockman et al. ${ }^{41}$ investigated the uptake of gallium nitrate in rats. This compound has been used for treatment of cancer patients suffering from accelerated bone resorption. Samples of rat tibia for analysis were obtained from animals treated with gallium nitrate in doses comparable to those used for treatment of human patients. Maps of the distribution of gallium and other elements were obtained using SRIXE. It was found that the gallium was preferentially absorbed in metabolically active regions in the metaphysis and in the endosteal and periosteal surfaces of diaphyseal bone where new bone formation and modeling occur. The results imply that the gallium enhances osteoblast function and decreases osteoclastic activity on a local scale. Changes in the iron and zinc concentrations also observed may help in searching for more refined explanations on a molecular level.

Similar experiments have been carried out to investigate the absorption of lead in bone ${ }^{42-44}$. Lead, even now, represents a serious threat to human health in the United States and elsewhere. Lead accumulates in the skeleton and is stored there with a residence time of one to two decades. Remodeling of the bone can cause release of the lead and thereby expose other organs of the body over long time periods. Maps made on sections of rat tibia indicate that the 
lead is located in a manner similar to that found for gallium. Changes in the morphology of the bone were also found to be caused by the lead exposure ${ }^{44}$.

The elemental distributions in growth plate cartilage from calf scapula and normal and arthritic equine cartilage were measured in a collaboration between groups from the University of Trieste and BNL. ${ }^{45}$ The growth plate measurements involved determinations of the major elements ( $\mathrm{Ca}$ and $\mathrm{S})$ and trace elements $(\mathrm{Ni}, \mathrm{Cu}, \mathrm{Zn}$ and $\mathrm{Sr})$. The distribution of $\mathrm{Ca}$ was consistent with known concepts of bone formation. S distributions are assumed to reveal the concentration of the S-containing proteoglycan molecules, and the $\mathrm{Zn}$ atoms are presumed to be bound to molecules of alkaline phosphatase. The Cu distribution was found to have a uniform distribution over the different zones of cartilage examined. This is consistent with assignment to lysil oxidase, an enzyme involved in collagen synthesis. Ni distributions were similar to those found for $\mathrm{Ca}$. However, it was not clear what the biological role of this element was. The measurements on equine cartilage were similar in approach with measurements made on $\mathrm{S}, \mathrm{Ca}$, and $\mathrm{Zn}$. In this study, marked differences are observed for the concentrations of these elements in the several components of the cartilage. It is also argued here that the zinc is present in the enzyme alkaline phosphatase.

The SRIXE approach makes possible multi-element maps at the trace element concentration level on the cartilage structure at a cellular size scale. The results obtained are in agreement with conclusions drawn from use of biochemical methods. In the future, aside from the implications of the biochemical results obtained, the microanalytical properties of SRIXE should result in its wide acceptance as a general tool for study of bone and cartilage. 


\subsection{Geological and extraterrestrial materials}

Synchrotron x-ray techniques including SRIXE, CMT, XANES/EXAFS, and diffraction have been widely employed for the characterization of geological materials. Our work at the NSLS covers several topics which illustrate this point. The main emphasis is on the use of CMT.

\subsubsection{H. Feng and K. W. Jones, Brookhaven National Laboratory; C. R. Hagelberg, Los Alamos National Laboratory; and M. Hiltl, Lawrence Livermore National \\ Laboratory. Microstructure of shock-recovered Berea sandstone}

The microstructure of shocked geological materials is of great interest. For example, data describing the three-dimensional pore structure of rocks can be used as input for making better models for predicting fluid flow in porous media which in turn can help in developing methods for improved techniques for oil and gas recovery. Another need is to obtain better understanding of changes in the structure when a shaped-charge is used to perforate an oil well casing to provide connectivity to the reservoir rock. We investigated samples obtained from shockrecovery experiments ${ }^{46}$ performed at LLNL using a single-stage light-gas gun and analyzed them using synchrotron CMT at BNL with a voxel size of $3.6 \mu \mathrm{m}$. It is possible to distinguish the differences between the undamaged (Figure 3.2-1) and shocked (Figure 3.2-2) materials and to explore the transition region between the two regions. Porosity measurements of the two regions give values of $21.0 \%$ and $13.3 \%$ for the undamaged and shocked regions, respectively. The value for the undamaged material is in agreement with the accepted value of $21.92 \%$. Detailed analysis of the tomographic data is now in progress to give the depth dependence of the porosity and to investigate the connectivity of the pore structure through the interface region. The use of 
synchrotron CMT is a useful complement and extension to analyses obtained with scanning electron microscopy and laser scattering techniques.

\subsubsection{H. Feng, K. W. Jones (BNL), G. F. Herzog, C. Schnabel (Rutgers University), and D. E. Brownlee (University of Washington, Seattle). Internal structure of two type-I deep-sea spheres by $x$-ray computed microtomography ${ }^{47}$}

CMT at high resolution makes it possible to explore the three-dimensional structures of small and scarce extraterrestrial objects such as micrometeorites. In particular, an experiment to ascertain the structure of the interiors of a subclass of micrometeorites known as type-I spheres ${ }^{48,49}$ was undertaken. The type-I spheres consist mainly of oxides of iron and nickel that formed as the precursor bodies passed rapidly through the Earth's atmosphere, melted, oxidized, and finally cooled abruptly on plunging into the ocean. Though small, the type-I spheres have fairly complex structures. By examining these structures, we obtain information about the changes the precursor bodies underwent and hence valuable clues to the original nature of the precursor bodies. CMT has the advantages of being non-destructive, fast, and producing digital data, which can readily be transformed and processed to reveal relationships that might otherwise be difficult to see.

In this experiment, we used a filtered white beam of $\mathrm{x}$-rays from a bending magnet. For these measurements, one volume element (voxel) corresponds to $3.6 \mu \mathrm{m}^{3}$. Data for sphere KK198-6, which were stored in a volume of $658 \times 658 \times 100$ voxels, took less than $2 \mathrm{~h}$ to acquire.

Representative tomographs (Figure 3.2-3) show many of the features previously reported for type-I spheres ${ }^{30}$. Most of the mass appears to consist of two oxide phases, probably magnetite $\left(\mathrm{Fe}_{3} \mathrm{O}_{4}\right)$ and wüstite (non-stoichiometric $\mathrm{FeO}$ ). Interestingly, in our suite of samples, 
we do not observe the eccentric metal beads commonly remarked by others (e.g., Castaing and Frederiksson $\left.{ }^{51}\right)$. Many spheres contain one compact $(<10 \mu \mathrm{m})$, high-attenuation feature close to the rim, which we interpret as an oxidation-resistant nugget rich in $\mathrm{Ni}$ and platinum-group elements. In the past, such nuggets have been found only through much more laborious experimental work ${ }^{52}$. The tomographs and independent measurements of density also establish for the first time the prevalence of holes (Figure 3.2-4) in the spheres, typically about $10-20 \%$ of the total volume. The holes normally emanate inward from a single circular entry point on the surface, branching as they go. Their locations, which tend to be antipodal to that of the nuggets, may reflect segregation of low- and high-density phases that accompanies the deceleration of a fluid. Possible explanations for the holes include the loss of a metal rich bead just before the molten sphere froze and the preservation, again through rapid quenching, of bubbles created by evaporation of the molten material.

\subsubsection{Hydrothermal vents}

Hydrothermal vent systems at the mid-ocean ridge are of great interest to marine geochemists and geologists ${ }^{53-56}$. The chemical reactions that occur in hydrothermal systems are largely the results of interactions between seawater and molten basalt. When the basalt cools and freezes, some elements are solubilized and others deposited. Hydrogenous deposits (or metalliferous sediments) commonly blanket the central rift valley and flanks of mid-ocean ridges and rises. In addition to metalliferous sediments, massive polymetallic sulfides are also observed in various stages of formation around hydrothermal vents. In the hydrothermal systems, the fluids that are emitted from hydrothermal vents are hot, acidic, and enriched in reduced trace metals and sulfides ${ }^{53}$. Some chemical reactions happen at a temperature of about $350^{\circ} \mathrm{C}$ in the 
vent system, releasing metals (e.g., $\mathrm{K}^{+}, \mathrm{Fe}^{2+}, \mathrm{Mn}^{2+}, \mathrm{Cu}^{2+}, \mathrm{Zn}^{2+}, \mathrm{Ca}^{2+}$, etc.) from basalts and producing mineral precipitation (e.g., $\mathrm{Mg}(\mathrm{OH}) \mathrm{SiO}_{3}, \mathrm{Fe}_{3} \mathrm{O}_{4}$, quartz, and pyrite). Lowtemperature $\left(<100^{\circ} \mathrm{C}\right)$ reactions occur when fluid has escaped into the deep ocean and heated sea water rises due to its decreased density, producing black and white smokers. The formation of black smokers is the consequence of little mixing of the fluid with "fresh" seawater and precipitation of metal sulfides ${ }^{53,55,57}$. Some of these particles deposit as chimneys. White smokers are the result of subsurface mixing (10-200 m below the sea floor). When these fluids enter the deep sea, the precipitates are milky white because they are primarily zinc sulfide ${ }^{53,55,57}$. As sulfides deposit within the chimneys, the hydrothermal flow eventually ceases and the sulfides oxidize, causing the chimneys to collapse into basal mounds.

The structure of hydrothermal vent samples has been investigated by Tivey ${ }^{56}$ and Tivey and $\mathrm{Singh}^{58}$. CMT was employed as a way to determine the distribution of sulfide and anhydrite materials, the morphology of flow conduits, and porosity. Their experiments utilized an industrial computed tomography (CT) scanner with a beam energy greater than $80 \mathrm{keV}$. The slice thickness was about $100 \mu \mathrm{m}$, and the horizontal pixel size was about $50 \mu \mathrm{m}$. Volume images were made by measuring sequential horizontal sections at $100 \mu \mathrm{m}$ and $1000 \mu \mathrm{m}$ steps. The diameter of the core samples was $2.5 \mathrm{~cm}$. Substantial information was obtained on the distribution of pore space and internal structures of the measured samples. However, it was pointed out that the grain sizes often encountered were in the range from $5 \mu \mathrm{m}$ to $50 \mu \mathrm{m}$. Hence, estimates of porosity and other parameters could be affected by the spatial resolution of the tomography. CMT measurements were made on several samples taken from the Mid-Atlantic Ridge using synchrotron computed microtomography at BNL with a voxel size of $3.6 \mu \mathrm{m}$. This resolution is approximately one order of magnitude smaller than the data obtained using an 
industrial scanner. Volume images from hydrothermal vent chimneys are shown for location SCT1 in Figure 3.2-5 and for SCT2 in Figure 3.2-6. The calculated porosities for SCT1 and SCT2 are 0.129 and 0.127 , respectively. The images displayed in the figures also show that there are variations in the composition of the materials that would not be observed with the resolutions obtained with the industrial scanner. It is concluded that the use of CMT combined with coarser scans will be essential for obtaining a more complete description of the materials obtained from the hydrothermal vent chimneys.

\subsubsection{H. Feng and K. W. Jones (BNL), S.-R. Song (Taiwan National University), U.}

Neuhaeusler, C. Jacobsen (State University of New York, Stony Brook), and N. Marinkov, Albert Einstein College of Medicine). Investigation of New York/New Jersey Harbor dredged material

Many sites in the United States are contaminated with organic and inorganic materials associated with the manufacture of goods, their use, and their disposal. Cleanup of these sites to meet present environmental standards entails the expenditure of large amounts of money and places a strong emphasis on the development of new decontamination methods that are both environmentally acceptable and economically affordable. One particularly challenging task is to cope with the contaminated sediments widely found in the ports, rivers, and lakes of the United States. These sediments often must be removed in order to reduce their direct environmental impact on the biota or to maintain navigational channels and other areas related to commercial shipping activities. The need for new treatment technologies and the problems of contaminated sediments have been reviewed recently $y^{59,60}$. 
A specific example of the effort to cope with the problem of contaminated sediments is given by work focused on the Port of New York and New Jersey. In this case, Congress has appropriated funding through the Water Resources Development Acts (1990, 1992, 1996, and 1999) for a program aimed at testing the effectiveness and economic feasibility of different treatment technologies. This is a phased program that is moving from bench-scale testing to deployment of full-scale facilities that can process from 76,000 to $190,000 \mathrm{~m}^{3}$ of sediment per year. The program is directed by the U. S. Environmental Protection Agency - Region 2 in collaboration with the U. S. Army Corps of Engineers - New York District, and the U. S. Department of Energy - Brookhaven National Laboratory. The aim is to target technologies which can be brought into operation without extensive research and development efforts. Nevertheless, as the work went forward it became clear that supplementary research work closely tied to the demonstrations would be useful. As a result, supporting experiments using several techniques were developed through use of other funding sources.

A sediment-washing technology is one method that is being brought into operation at the present time. This method uses high-pressure water jets combined with surfactants and chelators to separate organic materials from the sediments and to extract the metals. Points where more information would be useful include:

- Sedimentation processes

- Distribution of contaminants as a function of particle size

- Distribution of contaminants on individual particles

- Relationship of organic materials and sediment particles

- Nature of the organic materials found in the sediments

- Chemical state of the metal contaminants 
contamination on a limited number of grains. They also suggest that it would be difficult to make a physical separation of the sediments into clean and contaminated fractions.

Sediment-washing techniques that employ high-pressure water jets can be used to separate organic materials containing contaminants from the sediment grains. The effectiveness of the approach depends on the geometry of the organic material/sediment particle. The chemical state of the organic materials is also important for evaluation of the effectiveness of the treatment technology and for gaining understanding of possible methods for improving the treatment efficiency.

Soft x-ray microscopy can be used to investigate these questions. Neuhäusler et al ${ }^{64}$ used the instrumentation on the NSLS X1 beam line to investigate dilute specimens of sediment contained in a wet cell. Measurements were made above and below the $\mathrm{C} \mathrm{K}$-edge to show the spatial distributions of $\mathrm{C}$ and the sediment grains. In addition, XANES/EXAFS measurements were made to investigate differences in the form of $\mathrm{C}$ present in the sample. Images obtained above and below the $\mathrm{C} \mathrm{K}$-edge for particles taken from a sample of Newtown Creek, a highly contaminated waterway in New York City, are shown in Figure 3.2-9. It can be seen that the $\mathrm{C}$ is associated with the sediment grains and that the shape of the particles is highly irregular. These data are being used as input for a calculation that attempts to model the actual physical washing process. Results for absorption spectroscopy are shown in Figure 3.2-10. Here, there is evidence that different forms of carbon compounds exist not only in the contaminated sediments, but also in sediments that have been processed in a proprietary treatment developed by BioGenesis Enterprises of Milwaukee, Wisconsin.

The form of the organic compounds can also be investigated using Fourier Transform Infrared Radiation (FTIR) spectroscopy. In this case, the apparatus uses commercial 
spectrometers combined with high flux synchrotron IR beams to make measurements with a resolution of $15 \mu \mathrm{m}$. It was possible to conclude from these measurements that the washing process was successful in removing several contaminant peaks from the contaminated material. In addition, information is gained on the lipid and protein compounds present that will be helpful for understanding the importance of naturally occurring and contaminant organic materials.

\subsection{Environmental chemistry}

Environmental chemistry is a somewhat diffuse topic. It can certainly be considered to include experiments on the bioaccumulation of metals in bone or the fate and transport of contaminants in sediments. Osán and Török ${ }^{65}$ included measurements on aerosols, fly ash, and tree rings in a review of the environmental applications of SRIXE. In addition to the experiments mentioned above, we include here a discussion of recent work undertaken to investigate the uptake of metals in trees located on a contaminated site in Canada.

\subsubsection{R. R. Martin, T. K. Sham, G. W. Won, P. van der Heide, K. W. Jones, S-.R Song, and R. Protz. Secondary ion mass spectroscopy and synchrotron $x$-ray fluorescence in the study of the qualitative variation in metal content with time in tree rings ${ }^{66}$ Measurement of the microscopic distribution of metals in wood can be useful in} understanding their role in the normal growth of a tree. Metals deposited in soils as a result of anthropogenic activities may also be incorporated in the tissue structure of the wood. It is thus possible that the concentrations found in tree rings will reflect the time-dependent variation in the concentrations of the polluting elements. However, the pathways for uptake in the tree must be taken into account in searching for a correlation between time-dependent pollutant concentrations 
and the concentrations in the tree rings. The complexity of these pathways is such that it will be difficult to use tree ring concentrations as time-dependent pollution indicators until they are better understood. Submicrometer analysis of the metal distributions in wood will help to resolve them. This is reflected in several studies with conflicting findings. Work by Trueby ${ }^{67}$ finds no correlation while Qian et al. ${ }^{68}$ believe that there is one.

Measurements of the elemental concentrations in the rings need to be made using different analytical methods since the interest may be in accumulation of elements at the cellular level or in the concentrations averaged over a larger area in a given ring. Here, two complementary analytical methods were applied to the measurement of heavy elements in specimens taken from black spruce trees in northern Canada. Secondary ion mass spectrometry (SIMS) with a lateral resolution of about $10 \mu \mathrm{m}$ was used for high spatial resolution measurements. The depth of the material analyzed was less than $1 \mu \mathrm{m}$. SRIXE with a comparable lateral resolution was used with thick samples to obtain values averaged over the much larger volumes determined by the escape depth of the fluorescent $\mathrm{x}$ rays. These depths are appreciable even for light elements such as $\mathrm{Ca}(\sim 175 \mu \mathrm{m})$. Results from the two types of analytical measurements are shown in Figure 3.3-1 where SRIXE results for $\mathrm{Ca}, \mathrm{Fe}, \mathrm{Zn}$, and $\mathrm{Fe}$ are shown and compared with the SIMS results for Fe. The scan distance covers a time period of 7 years from 1920 to 1927 . The maxima shown are consistent with the annual growth rings over that period. The SIMS and SRIXE results are reasonably consistent considering the differences in volumes of material analyzed. The results also show that, in general, the elements observed do not rapidly diffuse through the wood structure. Hence, the ring contents do give an indication of the uptake of the elements as a function of time. Relation of these concentrations to the input from the pollutant sources needs to be investigated further. 


\subsection{Materials analysis}

The fields of material science and chemical science have benefited greatly from application of synchrotron-radiation based analytical methods. Studies of thermal spray materials, catalysts, and integrated circuit materials are presented that illustrate the usefulness of CMT and microdiffraction methods. Obviously, synchrotron $\mathrm{x}$-ray beams have been used intensively for years for materials studies and there is no intention here to give an exhaustive summary of all applications.

\subsubsection{Thermal spray}

Thermal spray is a widely used method for deposition of thermal barrier materials and other protective coatings for improvement of wear properties, increasing corrosion resistance, protection of parts in gas turbine engines, and formation of engineered structural materials. Problems related to the technology have been reviewed by Berndt et al ${ }^{69}$ They list questions requiring further investigation in the areas of plasma-particle interactions, deposit formation dynamics, thermal properties of thermal barrier coatings, mechanical properties of coatings, feedstock materials, porosity, and manufacture of intermetallics. CMT is cited as a method that provides data not provided by other techniques and that may help in developing correlations between quality and preparation conditions. Based on the experiment of Spanne et al. ${ }^{70}$, possible future development of the CMT method is discussed.

Spanne et al. ${ }^{70}$ used first-generation CMT to investigate two coatings of tungsten carbide/cobalt sprayed onto a steel substrate. They were produced so that it was expected that there would be differences in their porosity. The CMT work was carried out with bending magnet radiation from the NSLS which had low energy $\mathrm{x}$ rays removed by passage through a 254 
$\mu \mathrm{m}$ Hf foil. The resulting mean $\mathrm{x}$-ray energy was about $45 \mathrm{keV}$ with beam sizes of about 3-4

$\mu \mathrm{m}$. Histograms of the measured attenuation coefficients are shown in Figures 3.4-1 and 3.4-2. The difference in the composition of the two samples is clearly seen. The mean values of the attenuation coefficients are different by about $20 \%$, and the peak for the less dense material shows pronounced tailing on the low attenuation coefficient side. These two factors indicate a difference in the porosity of the two materials and show that the CMT method is an effective diagnostic method for study of these materials.

\subsubsection{Study of supported catalysts}

Catalysts are widely used for chemical processing, petroleum refining, and emission control. While investigations of their action often focus on reactions on surfaces at essentially the molecular level, there is also need to consider their behavior on larger size scales. In the latter case, the application of CMT can be useful.

Nichols et al. ${ }^{71}$ used a third-generation CMT apparatus ${ }^{72}$ for investigation of a simulated carbon-supported catalyst intended to simulate an electrode for a hydrogen battery. The resolution of the system was about $15 \mu \mathrm{m}$. The catalyst in this case was Pd deposited in a film about $5 \mu \mathrm{m}$ thick. A total of 300 tomographic slices were obtained so that it was possible to present the data in a three-dimensional format. Inspection of the tomographic sections and volume showed that the Pd was not deposited uniformly and that it is deposited in interior regions previously thought to be inaccessible to the deposition process.

A number of experiments were also carried out at Brookhaven using the NSLS and first-generation tomography apparatus. Three heterogeneous catalysts were measured: $\mathrm{Cr} / \mathrm{SiO}_{2}$ and $\mathrm{TiCl}_{3} / \mathrm{MgCl}_{2}$ catalysts used for polyethylene polymerization ${ }^{73,74,75,76,77}$, a rare-earth exchanged 
zeolite fluid catalytic cracking catalyst $(\mathrm{FCC})^{73}$, and a Ni-Mo hydrotreating catalyst ${ }^{73}$ for use in the refining of petroleum. Only single-slice data was taken in these experiments. The pixel sizes varied from experiment to experiment, but were about $3-10 \mu \mathrm{m}$ in general.

Measurements on the $\mathrm{Cr} / \mathrm{SiO}_{2}$ system showed that, under some conditions, the catalyst fragments tended to be swept to the periphery of the polymerization particles, but this was not found for the $\mathrm{TiCl}_{3} / \mathrm{MgCl}_{2}$ material. Analyses of the sections were made using two-point correlation theory to obtain surface areas and porosities. Measurements on the spent FCC material, which was a rare-earth exchanged Y-type zeolite, showed that the distribution of the catalyst in the microspheroidal particle of clay, silica, and alumina it was contained in was not uniform. Distribution of elements such as $\mathrm{V}, \mathrm{Fe}, \mathrm{Ni}$, and $\mathrm{Ti}$ were measured using SRIXE. Ti and $\mathrm{V}$ were distributed uniformly in the particle, while $\mathrm{Fe}$ and $\mathrm{Ni}$ were concentrated on the periphery. The combination of SRIXE and CMT are useful in understanding the accumulation and transport of contaminant metals in the catalyst pellet. CMT sections were also made on new and used hydrotreating pellets. The concentration of Mo was determined by taking the difference between sections measured below and above the Mo K-x ray absorption edge. Changes in the morphology of the pellets after use was also clearly seen.

These experiments demonstrate the power of CMT and SRIXE as analytical methods for the investigation of various types of catalysts. The use of third-generation tomography geometry and x-ray beams from third-generation synchrotron sources will greatly enhance the quality of the data. Introduction of more sophisticated analytical methods ${ }^{78}$, originally developed for analysis of geological samples, will make it possible to understand the three-dimensional structures in more detail. 


\subsubsection{Investigation of integrated circuit structures using CMT and microdiffraction}

Integrated circuits are a challenging analytical problem since they are threedimensional structures with features that have sub-micrometer dimensions. CMT is, in principle, a valuable method for making non-destructive measurements on materials such as these. The spatial resolutions needed make demands that are not met by the third-generation equipment now available because of limitations on detectors and optics of the detector viewing systems.

A solution to this problem has been described by Levine et al. ${ }^{79}$ They used a zone plate to focus $1.573-\mathrm{keV}$ x rays from an undulator source at the APS for a source size of $77 \mu \mathrm{m}$ to an object size of $200 \mathrm{~nm}$. The objective of the experiment was to image the structure of aluminum interconnects so the $\mathrm{x}$-ray energy was selected to be slightly above the $\mathrm{Al} \mathrm{K}$ edge at $1.559 \mathrm{keV}$ to obtain maximum absorption. The samples were then investigated using a first-generation technique. The beam was scanned over a $301 \times 301$ pixel matrix with step sizes of 77 and $57 \mathrm{~nm}$ in the $\mathrm{x}$ and $\mathrm{y}$ directions at 13 angles between $+/-69.2$ degrees. Although the number of projections is limited, it was found that it was possible to reconstruct the data and make tomographic views that showed the three-dimensional structure of a two-level Al integrated circuit interconnect.

Other aspects of integrated circuits have been investigated using x-ray microdiffraction. These aspects include investigation of electromigration-induced stress in $\mathrm{Al}$ conductors $^{80}$, substrate/thin-film interfaces ${ }^{81}$, and deformations caused by metallization features ${ }^{82}$. The work was carried out on two different beam lines at the NSLS. The x-ray beams were formed using both pinholes and capillary focussing optics to produce beams with diameters of roughly $2-15 \mu \mathrm{m}$. Standard $\mathrm{x}$-ray diffraction apparatus was then employed to accumulate $\mathrm{x}$-ray 
diffraction data. The small size and high flux of the $\mathrm{x}$-ray beams were the key factor in making these measurements feasible. 


\section{Summary}

We have outlined some of the technical details related to the use of synchrotron radiation for application of several analytical methods, principally CMT and SRIXE, to a variety of materials. The emphasis was on experiments done at the Brookhaven NSLS and especially on experiments where we were personally involved. Other experiments were discussed to illustrate specific points. Taken together, we believe that it is clear that there are important uses for these methods and that the scope of applications will grow in the future.

It also seems clear that there will be a growth in the number of beam lines suitable for microbeam analyses using several different techniques. This is true of the BNL X26A beam line where SRIXE, XANES, and EXAFS are presently feasible and where addition of CMT is under consideration. Other beam lines at the ESRF and APS are also using combinations of these methods on undulator beam lines. An experiment that illustrates this point was carried out by Isaacs et al. ${ }^{83}$ to investigate the composition and structure of rare earth activated phosphors. They worked on NSLS beam line X16C and applied SRIXE, $\mathrm{x}$-ray diffraction and XANES in the course of the work. The combination of these techniques in a single apparatus should have a major scientific impact in years to come. 


\section{Acknowledgements}

We thank S. R. Sutton, M. L. Rivers, A. Lanzirotti, S. G. Cargill III, and I. C. Noyan for helpful discussions and for permission to use several photographs and figures. We also thank Lore Barbier for her suggestions and for her essential and skilled work in preparing the manuscript for publication. 


\section{References}

1. H. Winick and S. Doniach, "Synchrotron Radiation Research" (Plenum Press, New York, 1980).

2. B. M. Gordon and K. W. Jones, in "Spectroscopic and Microscopic Imaging of the Chemical State", ed. Michael D. Morris (Marcel Dekker, Inc., New York, 1993), p. 303.

3. K. W. Jones, in "Handbook of X-Ray Spectrometry: Second Edition, Revised", eds. R. Van Grieken and A. Markowicz (Marcel Dekker, Inc., New York, 1999), in press.

4. K. W. Jones, in "Microscopic X-Ray Fluorescence Analysis", eds. K. Janssens, A. Rindby, and F. Adams (John Wiley \& Sons Ltd., Sussex, England, 1999), in press.

5. Sz. Török, K. W. Jones, and C. Tuniz, in "Nuclear Methods in Mineralogy and Geology, Techniques and Applications", eds. A. Vértes, S. Nagy, and K. Süvegh (Plenum Press, New York, 1998), p. 217.

6. P. Chevallier and P. Dhez, in "Accelerator-Based Atomic Physics Techniques and Applications", eds. S. M. Shafroth and J. C. Austin (American Institute of Physics, New York, 1997), p. 309.

7. S. Hayakawa and Y. Gohshi, in "Applications of Synchrotron Radiation to Materials Analysis", eds. H. Saisho and Y. Gohshi (Elsevier Science B. V., Amsterdam, 1996), p. 171.

8. J. V. Smith, The Analyst 120, 1231 (1995).

9. J. V. Smith and M. L. Rivers, in "Microprobe Techniques in the Earth Sciences", eds. P. Potts, J. F. W. Bowles, S. J. B. Reed, and M. R. Cave (Chapman and Hall, London, 1995), p. 163. 
10. D. G. Schulze, J. W. Stucki, and P. M. Bertsch, eds., "Synchrotron X-ray Methods in Clay Science, Volume 9, CMS Workshop Lectures" (The Clay Mineral Society, Boulder, 1999), 224 pp.

11. David B. Guralnik, "Webster's New World Dictionary, Second College Edition (Prentice Hall Press, New York, 1986).

12. http://physics.nist.govPhysRefData/contents.html.

13. P. Kirkpatrick and A. V. Baez, J. Opt. Soc. Am. 39, 766 (1948).

14. R. D. Giauque, A. C. Thompson, J. H. Underwood, Y. Wu, K. W. Jones, and M. L. Rivers, Anal. Chem. 60, 855 (1988).

15. S. R. Sutton, M. L. Rivers, P. J. Eng, and G. Shea-McCarthy, in National Synchrotron Light Source Activity Report 1997”, BNL 52540, p. B-238, May 1998.

16. S. A. Hoffman, D. J. Thiel, and D. H. Bilderback, Optical Engineering 33, 303 (1994).

17. P. Engstrom and C. Riekel, J. Synchrotron Rad. S3, 97 (1996).

18. G. S. Cargill III, K. Hwang, J. W. Lam, P.-C. Wang, E. Liniger, and I. C. Noyan, SPIE Proceedings 2516, 120 (1995).

19. G. S. Brown and S. Doniach, in "Synchrotron Radiation Research", eds. H. Winick and S. Doniach (Plenum Press, New York, 1980), p. 353.

20. G. S. Brown, in "Synchrotron Radiation Research", eds. H. Winick and S. Doniach (Plenum Press, New York, 1980), p. 387.

21. F. W. Lytle, G. H. Via, and J. H. Sinfelt, in "Synchrotron Radiation Research", eds. H. Winick and S. Doniach (Plenum Press, New York, 1980), p. 401.

22. S. Doniach, P. Eisenberger, and Keith O. Hodgson, in "Synchrotron Radiation Research, eds. H. Winick and S. Doniach (Plenum Press, New York, 1980), p. 425. 
23. D. C. Koningsberger and R. Prins, "X-Ray Absorption. Principles, Applications, Techniques of EXAS, SEXAFS, and XANES" (Wiley and Sons, New York, 1988), 673 pp.

24. S. Fendorf, in "Synchrotron X-ray Methods in Clay Science, Volume 9, CMS Workshop Lectures", eds. D. G. Schulze, J. W. Stucki, and P. M. Bertsch (The Clay Minerals Society, Boulder, 1999), p. 19.

25. P. Spanne and M. L. Rivers, Nucl. Instrum. Methods B24/25, 1063 (1987).

26. K. L. D'Amico, H. W. Decamp, J. H. Dunsmuir, B. P. Flannery, and W. G. Roberge, Rev. Sci. Instrum. 60, 1524 (1989).

27. B. P. Flannery, H. W. Deckman, W. Roberge, and K. L. D'Amico, Science 237, 1439 (1987).

28. U. Bonse, Q. C. Johnson, M. C. Nichols, R. Nuflhardt, S. Krasnicki, and J. Kinney, Nucl. Instrum. Methods A246, 644 (1986).

29. J. Kinney, Q. C. Johnson, M. C. Nichols, U. Bonse, and R. Nuflhardt, Appl. Optics 25, $4583(1986)$.

30. B. A. Dowd, A. B. Andrews, R. B. Marr, D. P. Siddons, K. W. Jones, and A. M. Peskin, in "Advances in X-Ray Analysis", Volume 42 (1999).

31. Betsy A. Dowd, Graham H. Campbell, Robert B. Marr, Vivek Nagarkar, Sameer Tipnis, Lisa Axe, D. Peter Siddons, SPIE Proceedings 3772, 224 (1999).

32. K. Themner, P. Spanne, and K. W. Jones, Nucl. Instrum. Methods B49, 52 (1990).

33. D. N. Slatkin, A. L. Hanson, K. W. Jones, H. W. Kraner, J. B. Warren, and G. C. Finkel, Nucl. Instrum. Methods 227, 378 (1984). 
34. P. T. Singer, R. P. Carty, L. E. Berman, I. Schlichting, A. Stock, A. Smalås, Z. Cai, W. F. Mangel, K. W. Jones, and R. M. Sweet, Phil. Trans. R. Soc. Lond. A 340, 285 (1992).

35. Hollis T. Cline, Sonia Witte, and Keith W. Jones, Proc. Natl. Acad. Sci. USA, 93, 9915 (1996).

36. Thomas Pfister, Keith W. Jones, and Eckard Wimmer, J. Virology 74(1), 334 (2000).

37. T. Pfister, E. Wimmer, H. Feng, and K. W. Jones, in "National Synchrotron Light Source Activity Report 1999", in press.

38. Process Analytics, Orem, Utah.

39. G. Newman, S. Trowbridge, and K. W. Jones, in "National Synchrotron Light Source Activity Report 1996", BNL 52517, p. B-227, May 1997.

40. S. Yasumura, K. Jones, P. Spanne, G. Schidlovsky, L. Wielopolski, X. Ren, D. Glaros, and Y. Xatzikonstantinou, in "Proceedings of a Symposium on Aging and Body Composition: Technological Advances and Physiological Interrelationships, $76^{\text {th }}$ Annual Meeting of the Federation of American Societies for Experimental Biology", eds. S. B. Heymsfield and S. Yasumura (American Institute of Nutrition, 1993), p. 459.

41. R. S. Bockman, M. A. Repo, R. P. Warrell, Jr., J. G. Pounds, G. Schidlovksy, B. M. Gordon, and K. W. Jones, Proc. Natl. Acad. Sci. USA 87, 4149 (1990).

42. K. W. Jones, G. Schidlovsky, D. E. Burger, F. L. Milder, and H. Hu, in "Advances in In Vivo Body Composition Studies", eds. S. Yasumura, J. E. Harrison, K. G. McNeill, A. D. Woodhead, and F. A. Dilmanian (Plenum Press, New York, 1990), p. 281.

43. K. W. Jones, R. S. Bockman, and F. Bronner, NeuroToxicology 13, 835 (1992).

44. K. W. Jones, W. J. Berry, D. J. Borsay, H. T. Cline, W. C. Conner, Jr., and C. S. Fullmer, X-Ray Spectrometry 26, 350 (1997). 
45. R. Rizzo, M. Grandolfo, C. Godeas, K. W. Jones, and F. Vittur, J. of Experimental Zoology 273, 82 (1995).

46. M. Hiltl, C. R. Hagelberg, R. P. Switft, T. C. Carney, and W. J. Nellis, in "Proceedings, International Association for the Advancement of High Pressure Science and Technology (AIRAPT) International Conference on High Pressure Science and Technology (AIRAPT-17), July 25 - July 30, 1999, University of Hawaii, Honolulu, Hawaii, USA."

47. H. Feng, K. W. Jones, B. Stewart, G. F. Herzog, C. Schnable, and D. E. Brownlee, Lunar Planet. Sci. XXX, Abstract \#1209 (Lunar and Planetary Institute, Houston, Texas, 1999), (CD-ROM).

48. D. E. Brownlee, Annual Reviews of Earth and Planetary Science 13, 147 (1985).

49. G. F. Herzog, S. Xue, G. S. Hall, L. E. Nyquist, C.-Y. Shih, H. Wiesmann, and D. E. Brownlee, Geochim. Cosmochim. Acta 63B, 1443 (1998).

50. A. Kosakevitch and J. R. Disnar, Geochim. Cosmochim. Acta 61, 1073 (1997).

51. R. Castaing and K. Fredriksson, Geochim. Cosmochim. Acta 14, 114 (1958).

52. Ph. Bonté, C. Jéhanno, MM. Maurette, and D. E. Brownlee, in "Proceedings of the $17^{\text {th }}$ Lunar and Planetary Science Conference, Part 2", J. Geophys. Res. 92, E641 (1987).

53. J. M. Edmond and K. Van Damm, Scientific American 248, 78 (1983).

54. H. W. Jannasch and M. J. Mottl, Science 229, 719 (1985).

55. K. L. Van Damm, Annu. Rev. Earth Planet. Sci. 18, 173 (1990).

56. M. K. Tivey, in "Proceedings of the Ocean Drilling Program, Scientific Results", eds. P. M. Herzig, S. E. Humphris, D. J. Miller, and R. A. Zierenberg, Volume 158, 201 (1998).

57. S. M. Libes, “An Introduction to Marine Biogeochemistry" (John Wiley \& Son, Inc., New York, 1992). 
58. M. K. Tivey and S. Singh, Geology 25, 931 (1997).

59. Committee on Innovative Remediation Technologies, Innovations in Ground Water and Soil Cleanup, from Concept to Commercialization (National Academy Press, Washington, DC, 1997).

60. Committee on Contaminated Marine Sediments. Contaminated Sediments in Ports and Waterways, Cleanup Strategies and Technologies (National Academy Press, Washington, DC, 1997).

61. D. Coelho, J.-F. Thovert, and P. M. Adler, Phys. Rev. E 55, 1959 (1997).

62. J. Quintanilla and S. Torquato, Phys. Rev. E 55, 1558 (1997).

63. K. W. Jones, S.-R. Song, R. C. Klein, and G. Shea-McCarthy. Presented at 1997 Spring Meeting of American Geophysical Union, Baltimore, Maryland, May 1997.

64. U. Neuhäusler, S. Abend, S. Ziesmer, D. Schulze, D. Stott, K. Jones, H. Feng, C. Jacobsen, and G. Lagaly, in "Proceedings of VIth International Conference on X-Ray Microscopy (XRM99)", in press (1999).

65. J. Osán and S. Török, in "Chemical Applications of Synchrotron Radiation", ed. T. K. Sham (World Scientific Publishing Co., Inc.), Chapter 10, in press.

66. R. R. Martin, T. K. Sham, G. W. Won, P. van der Heide, K. W. Jones, S.-R. Song, and R. Protz, Can J. For. Res. 28, 1464 (1998).

67. P. Trueby, Angew. Bot. 69, 135 (1995).

68. J.-L. Quian, S.-Z. Huang, and C.-X. Xiang, Pedosphere 3, 109 (1993).

69. C. A. Berndt, W. Brindley, A. N.Goland, H. Herman, D. L. Houck, K. Jones, R. A. Miller, R. Neiser, W. Riggs, S. Sampath, M. Smith, and P. Spanne, J. Thermal Spray Technology 1, 341 (1992). 
70. P. Spanne, K. W. Jones, H. Herman, and W. L. Riggs, J. Thermal Spray Technology 2, 121 (1993).

71. M. C. Nichols, J. H. Kinney, Q. C. Johnson, R. A. Saroyan, U. Bonse, R. Nusshardt, and R. Pahl, Rev. Sci. Instrum. 60, 2475 (1989).

72. U. Bonse, R. Nusshardt, F. Busch, R. Pahl, Q. C. Johnson, J. H. Kinney, R. Saroyan, and M. C. Nichols, Rev. Sci. Instrum. 60, 2478 (1989).

73. W. C. Conner, S. W. Webb, P. Spanne, and K. W. Jones, Macromolecules 23, 4742 (1990).

74. K. W. Jones, P. Spanne, S. W. Webb, W. C. Conner, R. A. Beyerlein, W. J. Reagan, and F. M. Dautzenberg, Nucl. Instrum. Methods B57/57, 427 (1991).

75. K. W. Jones, P. Spanne, W. B. Lindquist, W. C. Conner, and M. Ferrero, Nucl. Instrum. Methods B68, 105 (1992).

76. W. C. Conner, M. Ferrero, S. Webb, R. Sommer, M. Chiovetta, K. Jones, and P. Spanne, in "Proc. $10^{\text {th }}$ International Congress on Catalysis, Budapest Hungary, July 1992", eds. L. Guczi et al. (Elsevier Science Publishers B. V., 1993), p. 1827.

77. M. A. Ferrero, R. Sommer, P. Spanne, K. W. Jones, and W. Curtis Conner, J. Polymer Science: Part A: Polymer Chemistry 31, 2507 (1993).

78. W. B. Lindquist, S.-M. Lee, D. A. Coker, K. W. Jones, and P. Spanne, J. Geophys. Res. 101, 8297 (1996).

79. Z. H. Levine, A. R. Kalukin, S. P. Frigo, I. McNulty, and M. Kuhn, Appl. Phys. Letters 74, 150 (1999).

80. P.-C. Wang, G. S. Cargill III, I. C. Noyan, and C.-K. Hu, Appl. Phys. Letters 72, 1296 (1998). 
81. I. C. Noyan, J. Jordan-Sweet, E. G. Liniger, and S. K. Kaldor, Appl. Phys. Letters 72, 3338 (1998).

82. I. C. Noyan, P.-C. Wang, S. K. Kaldor, and J. L. Jordan-Sweet, Appl. Phys. Letters 74, 2352 (1999).

83. E. D. Isaacs, M. Marcus, G. Aeppli, X.-D. Xiang, X.-D. Sun, P. Schultz, H.-K. Kao, G. S. Cargill III, and R. Haushalter, Appl. Phys. Letters 73, 1820 (1998). 
7. Table 1. Minimum detection limits for KB mirror demonstration at the NSLS

\begin{tabular}{|c|c|}
\hline Element & $\begin{array}{c}\text { Minimum Detection Limit } \\
\mathbf{F g} / \mathbf{1 0} \mu \mathbf{m} \mathbf{\times} \mathbf{1 0} \mathbf{~} \mathbf{m}\end{array}$ \\
\hline $\mathrm{K}$ & 70 \\
\hline $\mathrm{Ca}$ & $\mathbf{2 0}$ \\
\hline $\mathrm{Ti}$ & 3 \\
\hline $\mathrm{Mn}$ & 3 \\
\hline $\mathrm{Fe}$ & 2 \\
\hline $\mathrm{Ni}$ & 3 \\
\hline $\mathrm{Cu}$ & 3 \\
\hline $\mathrm{Zn}$ & \\
\hline
\end{tabular}




\section{Figure Captions}

Figure 2.1-1. The performance of a bending magnet at the NSLS is shown for a stored electron beam current of $500 \mathrm{~mA}$, the NSLS design value. Values for brilliance, brightness, and flux are shown in Figures $2.1-1 \mathrm{a},-1 \mathrm{~b}$, and -1c, respectively. (From K. W. Jones, B. M. Gordon, A. L. Hanson, W. M. Kwiatek, and J. G. Pounds, Ultramicroscopy 24, 313 (1988.)

Figure 2.3-1 Schematic diagram of the NSLS X26A beam line with monochromator and KB mirror focusing. (Drawing courtesy of A. Lanzirotti, University of Chicago.)

Figure 2.3-2. Photograph of the NSLS X26A x-ray microprobe. Components of the microprobe are identified in the photograph. (Photograph courtesy of A. Lanzirotti, University of Chicago.)

Figure 2.3-3. Typical x-ray spectra for thin film Standard Reference Materials 1832 and 1833 from the National Bureau of Standards obtained using the NSLS X26A KB system. (Courtesy of A. Lanzirotti, University of Chicago.)

Figure 2.3-4. Photograph of the University of Chicago Consortium of Advanced Radiation Sources (CARS) Geology, Soil, and Environmental subgroup KB mirror microprobe system at Sector 13 of the APS. (Photograph courtesy of S. R. Sutton, University of Chicago.)

Figure 2.3-5. Demonstration of sub-micrometer spatial resolution attained with the CARS KB microprobe system. The measurement was made by scanning a knife edge through the beam and observing the fluorescent $\mathrm{x}$ rays produced. (P. J. Eng, M Newville, M. L. Rivers, and S. R. Sutton, SPIE Proceedings 3449, 145 (1998).) 
Figure 2.5-1 Schematic diagram of the CMT system at the NSLS X27A beam line. (From Ref. 30.)

Figure 2.5-2 Photograph of the NSLS X27A CMT system hardware. The x-ray beam travels from right-to-left in the picture.

Figure 2.6-1. Energy spectrum of $x$ rays produced in the 90-degree scattering of the NSLS white beam from a $3.5-\mu \mathrm{m}$ polyester film. Mass loss of a sample following irradiation can be estimated from changes in the intensity of the scattered $x$ rays. (From Ref. 32.)

Figure 2.6-2. The relative intensity of $x$ rays scattered from a skin sample, taken as an example of a biological specimen, is shown as a function of absorbed dose. The change in the number of scattered $x$ rays shows the mass loss caused by the irradiation. (From Ref. 32.)

Figure 3.1-1 Portions of the SRIXE spectrum obtained from $\mathrm{x}$-ray analysis of the composition of a thin-section of tadpole optic tectum are shown. $\mathrm{Pb} \mathrm{L} \alpha$ and $\mathrm{Zn} \mathrm{K \alpha} \times$ rays are clearly observed. The lead $\mathrm{L} \alpha$ line is shown in (a) and the $\mathrm{Cu} \mathrm{K \alpha}, \mathrm{Zn}$ K $\alpha$ and $\mathrm{Zn}$ $\mathrm{K} \beta$ lines in (b). (From Ref. 44.)

Figure 3.2-1 Tomographic volume showing the structure of an undamaged Berea sandstone sample prior to shock loading. The voxel size is $3.6 \mu \mathrm{m}$. (From H. Feng, K. W. Jones, C. Hagelberg, and M. Hiltl, in "National Synchrotron Light Source Activity Report 1999", in press.) 
Figure 3.2-2 Tomographic volume showing the structure of a Berea sandstone following shock loading of the dry specimen. at about 6.1 Gpa. (From H. Feng, K. W. Jones, C. Hagelberg, and M. Hiltl, in "National Synchrotron Light Source Activity Report 1999", in press.)

Figure 3.2-3 Tomographic section of a micrometeorite showing existence of a nugget of $\mathrm{Ni}$ and platinum-group elements at the surface of the micrometeorite. The voxel size is $2.3 \mu \mathrm{m}$. The color scale shows the relative $\mathrm{x}$-ray attenuation coefficient. (From Ref. 47.)

Figure 3.2-4 Tomographic volume showing the structure of a hole in a micrometeorite. The existence of this type of hole is a common feature of this type of micrometeorite. The voxel size is $3.6 \mu \mathrm{m}$. (From Ref. 47.)

Figure 3.2-5 Internal microstructure of a hydrothermal vent chimney sample from location SCT1 at the Mid-Atlantic Ocean Ridge. The voxel size is $3.6 \mu \mathrm{m}$. (From H. Feng and K. W. Jones, in "National Synchrotron Light Source Activity Report 1999", in press.)

Figure 3.2-6 Internal microstructure of a hydrothermal vent chimney sample from location SCT2 at the Mid-Atlantic Ocean Ridge. The voxel size is $3.6 \mu \mathrm{m}$. (From H. Feng and K. W. Jones, in "National Synchrotron Light Source Activity Report 1999", in press.)

Figure 3.2-7 Tomographic volume obtained for a sandy sediment. The voxel size is $6.8 \mu \mathrm{m}$. The microstructure of the sediment is clearly displayed. . (From H. Feng and K. W. Jones, in "National Synchrotron Light Source Activity Report 1999", in press.) 
Figure 3.2-8 Results of SRIXE measurements of $\mathrm{Cr}$ distributions on individual particles from a sediment specimen obtained from New York Harbor. Results are shown for several grain-size ranges.

Figure 3.2-9 High-resolution x-ray microscopy images obtained above and below the $\mathrm{C}$ K-edge for particles taken from a sample of Newtown Creek, New York. The results clearly delineate the structures of the organic and inorganic components of the sediments.

Figure 3.2-10 Infrared spectra obtained using the Fourier Transform Infrared Spectrometer at the NSLS U2B beam line. Spectra are shown for data obtained from a specimen of sediment taken from Newtown Creek in New York Harbor and from a specimen of the same material following treatment of the sediment with a sediment washing technology. Differences in the organic compounds present can be seen.

Figure 3.3-1 Relative concentrations of $\mathrm{Ca}, \mathrm{Fe}, \mathrm{Zn}$, and Fe obtained using SRIXE are shown for a scan over a thick section of wood representing several years of growth. The results for Fe are compared with results found for the same material using SIMS. The information gained by use of the two techniques are discussed by Martin et al. $^{66}$ (From Ref. 66.)

Figure 3.4-1 Histogram of the frequency of occurrence of the reconstructed linear attenuation coefficients found in the picture elements of a tomographic section of a thermal spray specimen produced by an externally injected plasma. (From Ref. 70.)

Figure 3.4-2 Histogram of the frequency of occurrence of the reconstructed linear attenuation coefficients found in the picture elements of a tomographic section of a thermal spray specimen produced by an internally injected plasma. (From Ref. 70.) 


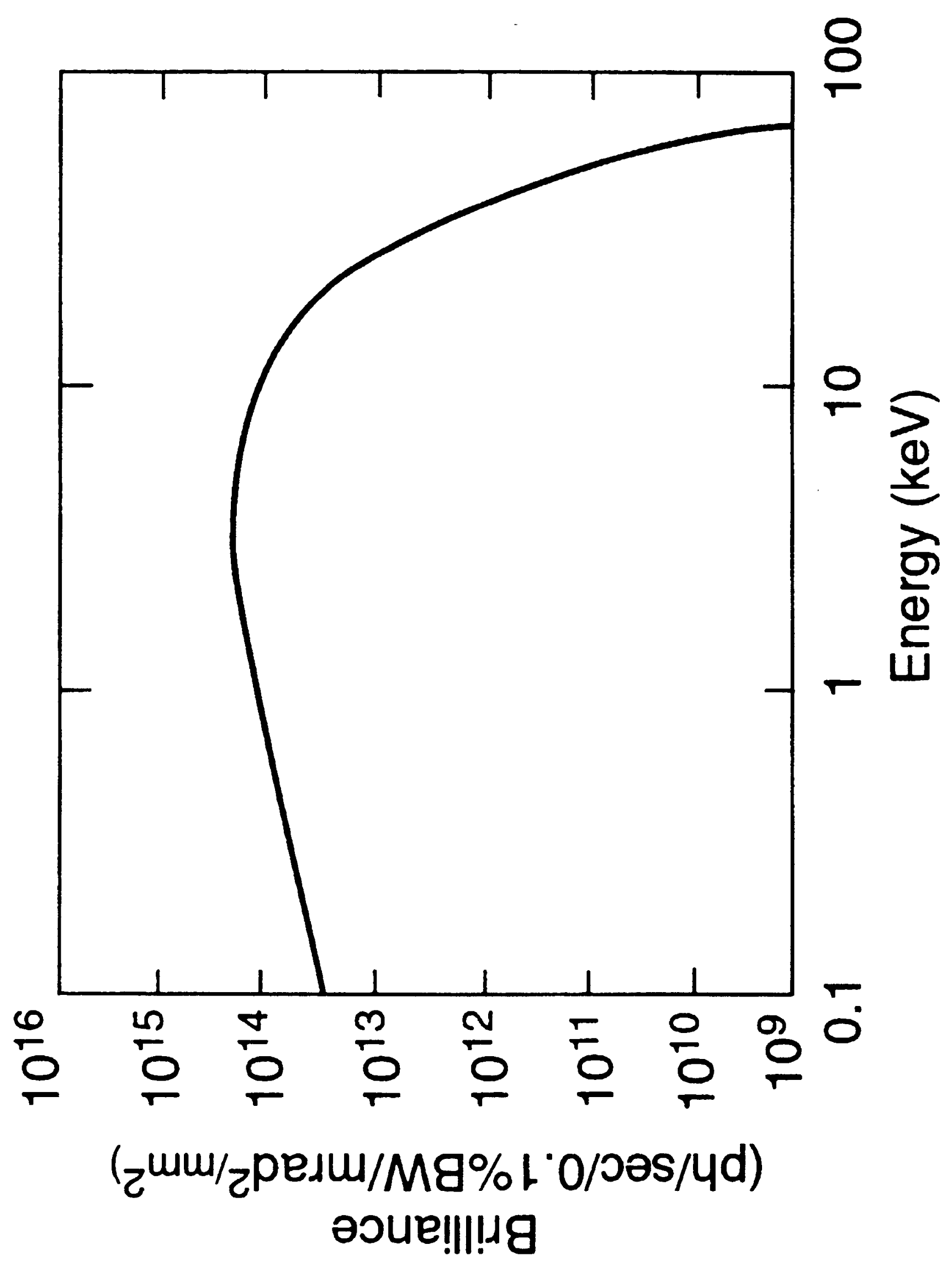




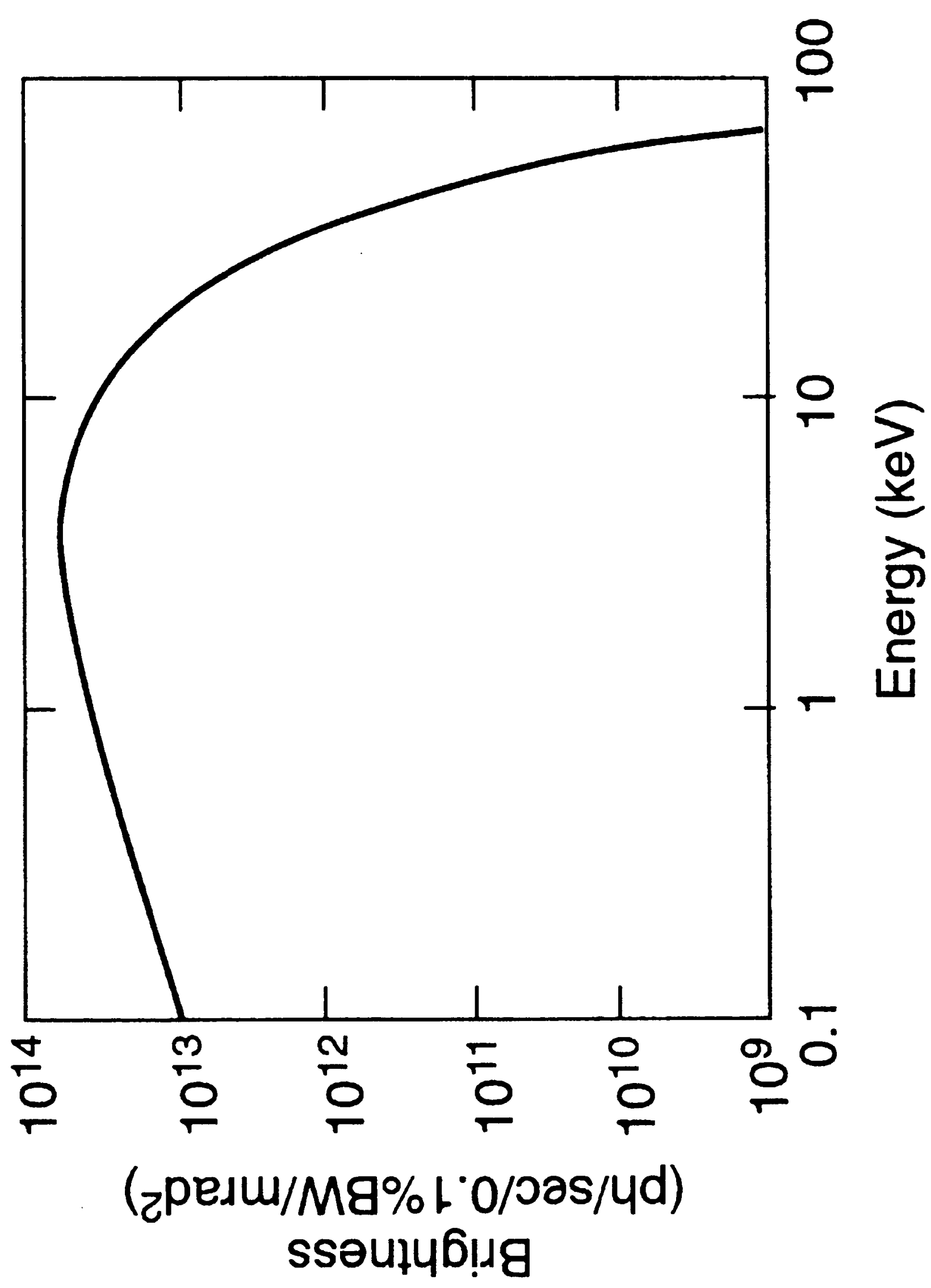




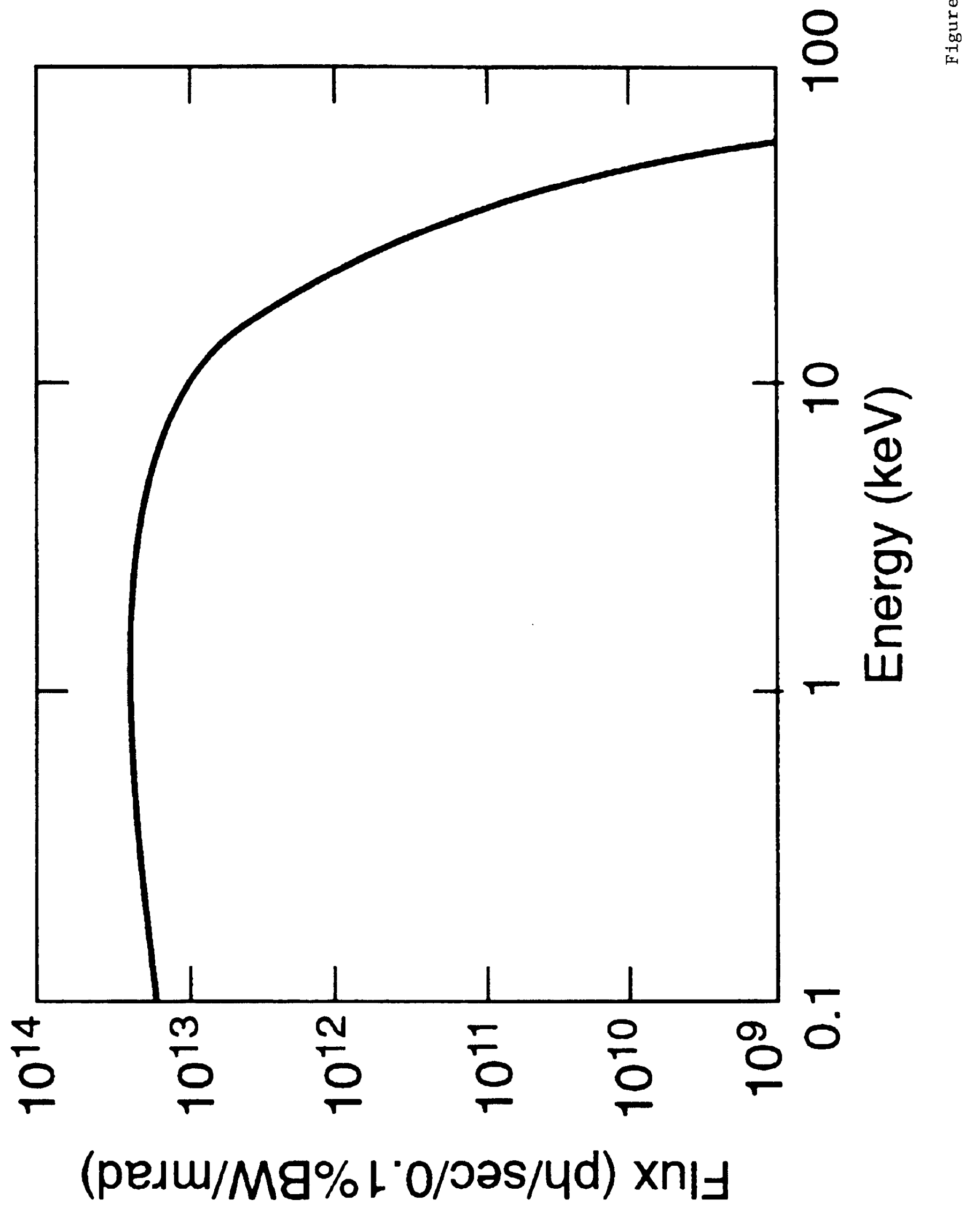




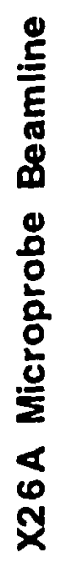
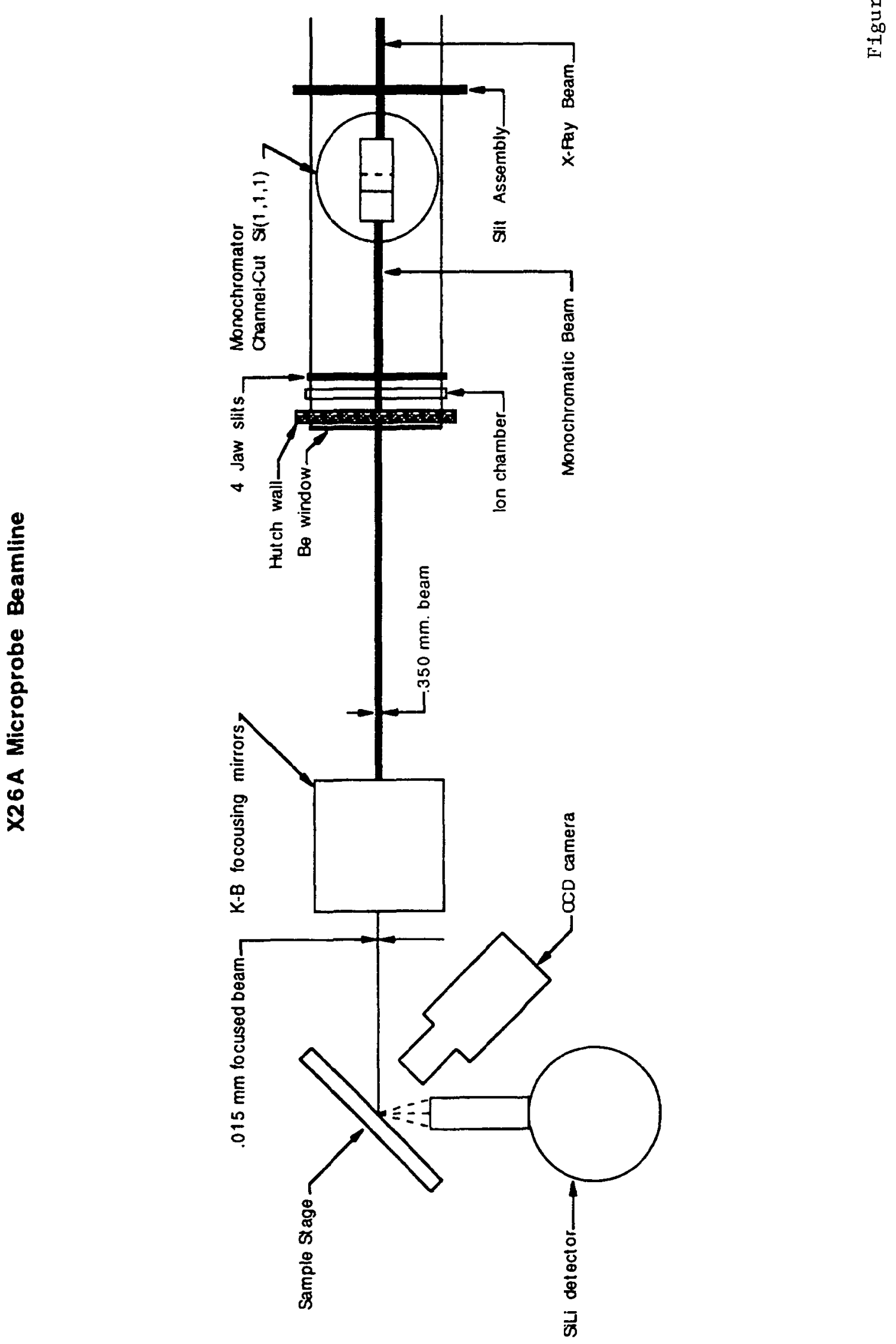


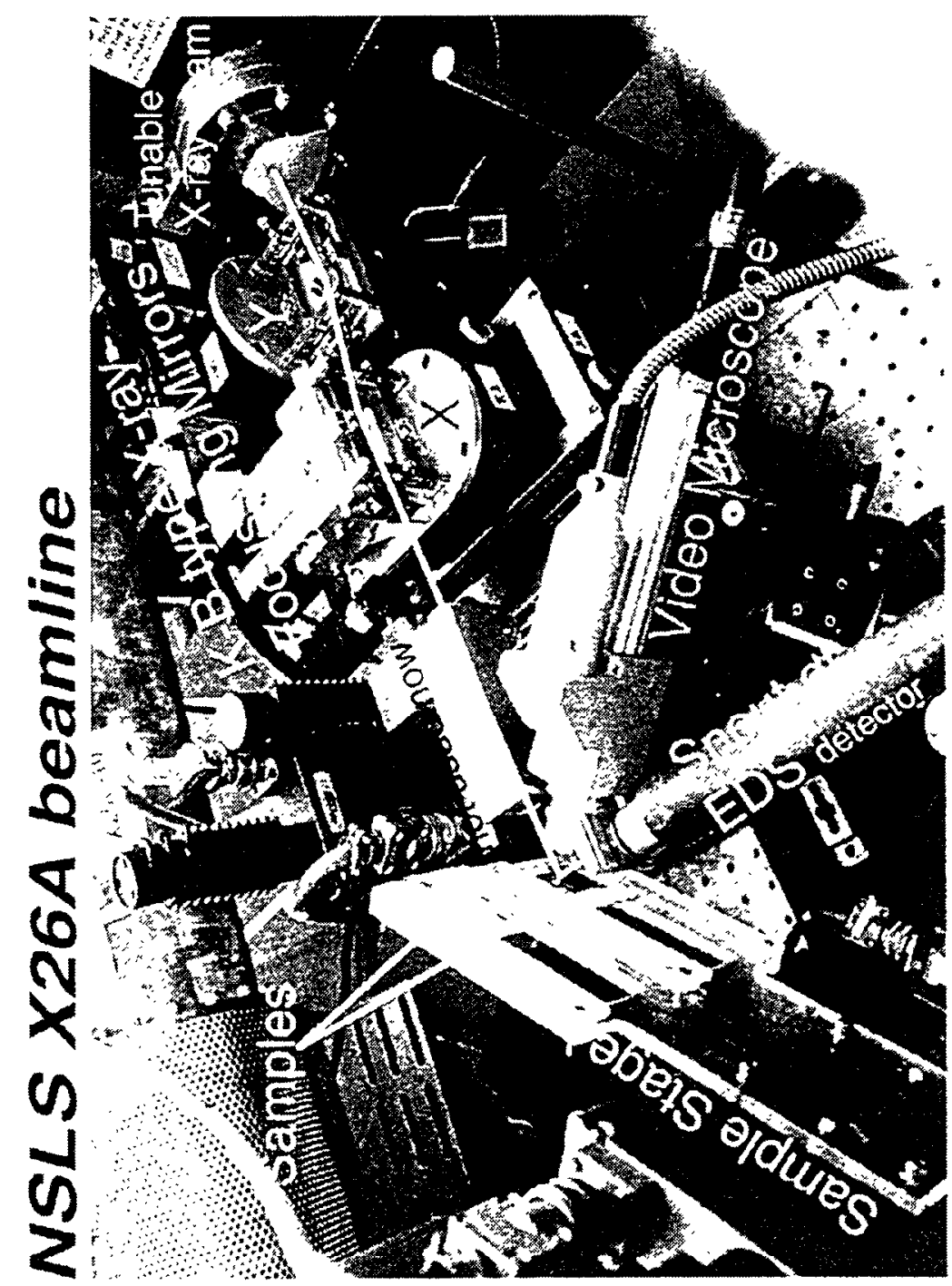



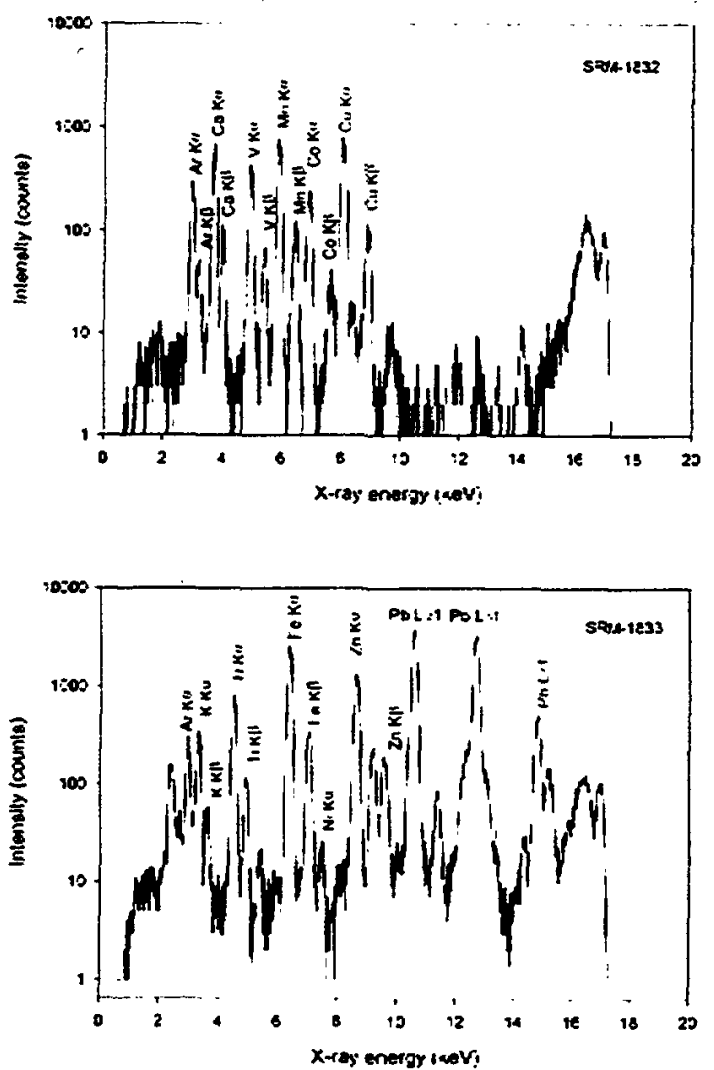

Figure 2.3-3 



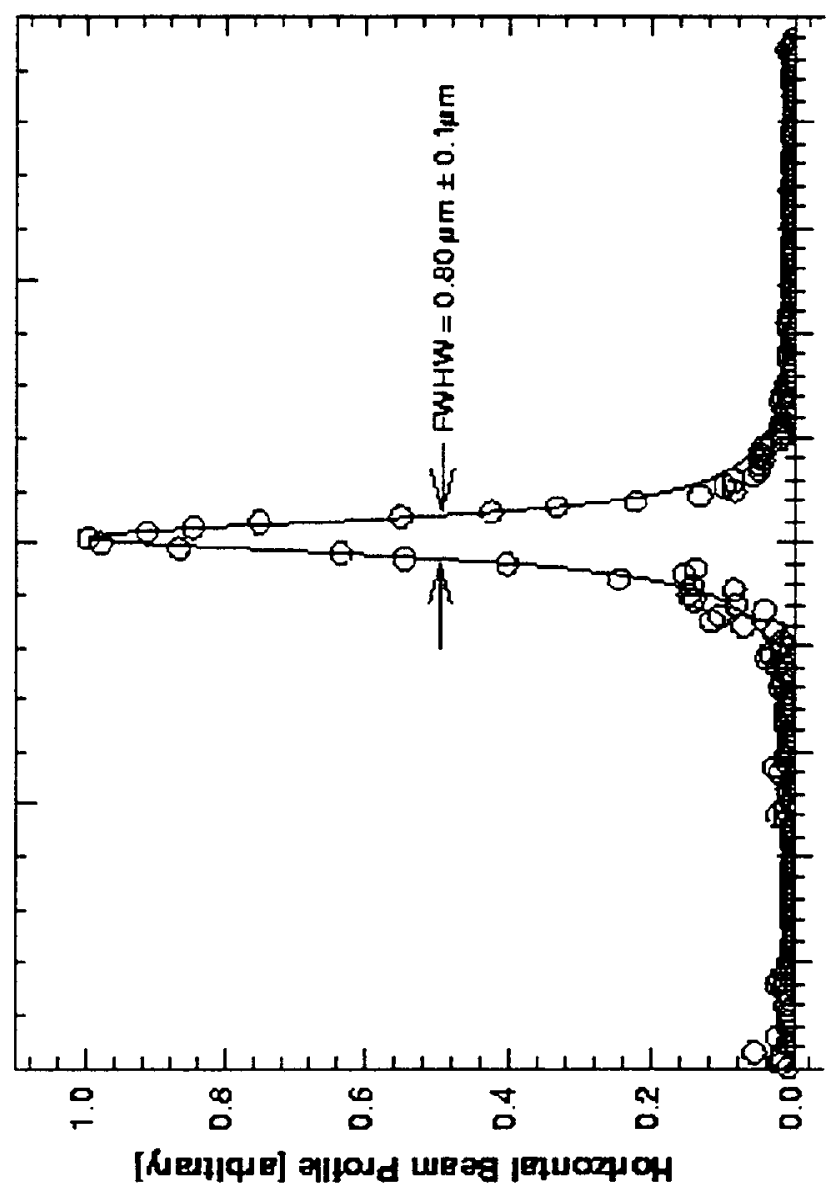




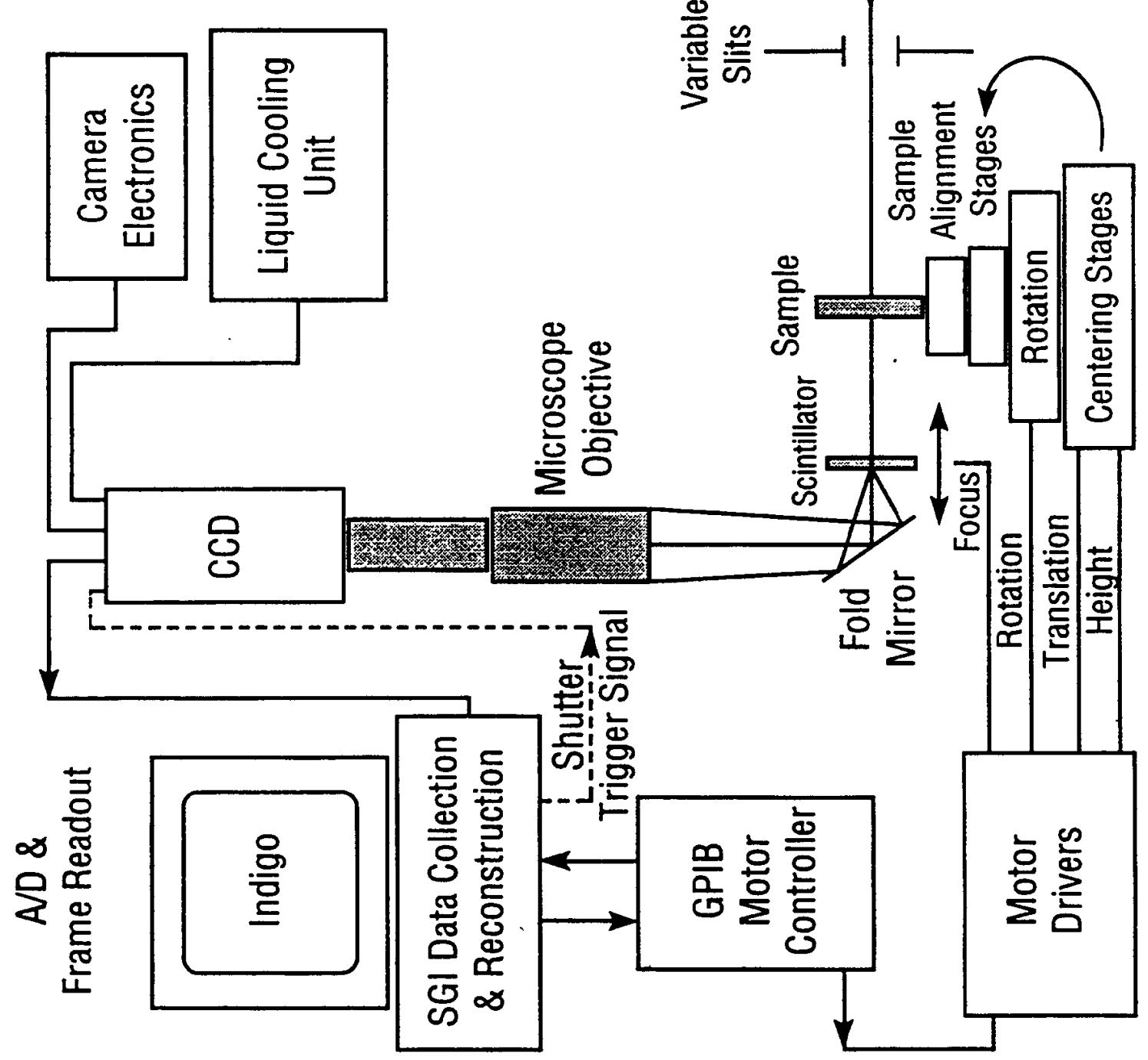




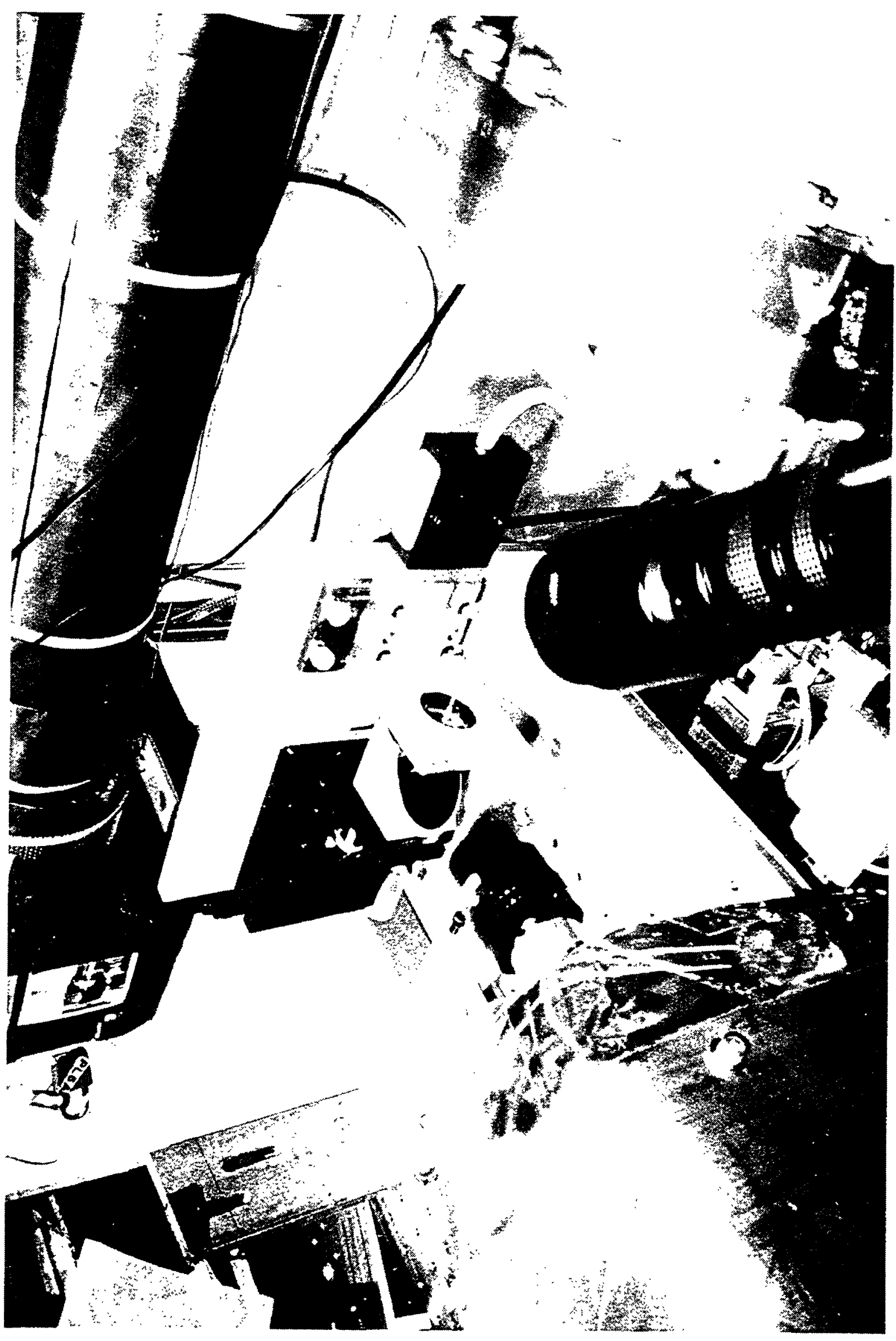




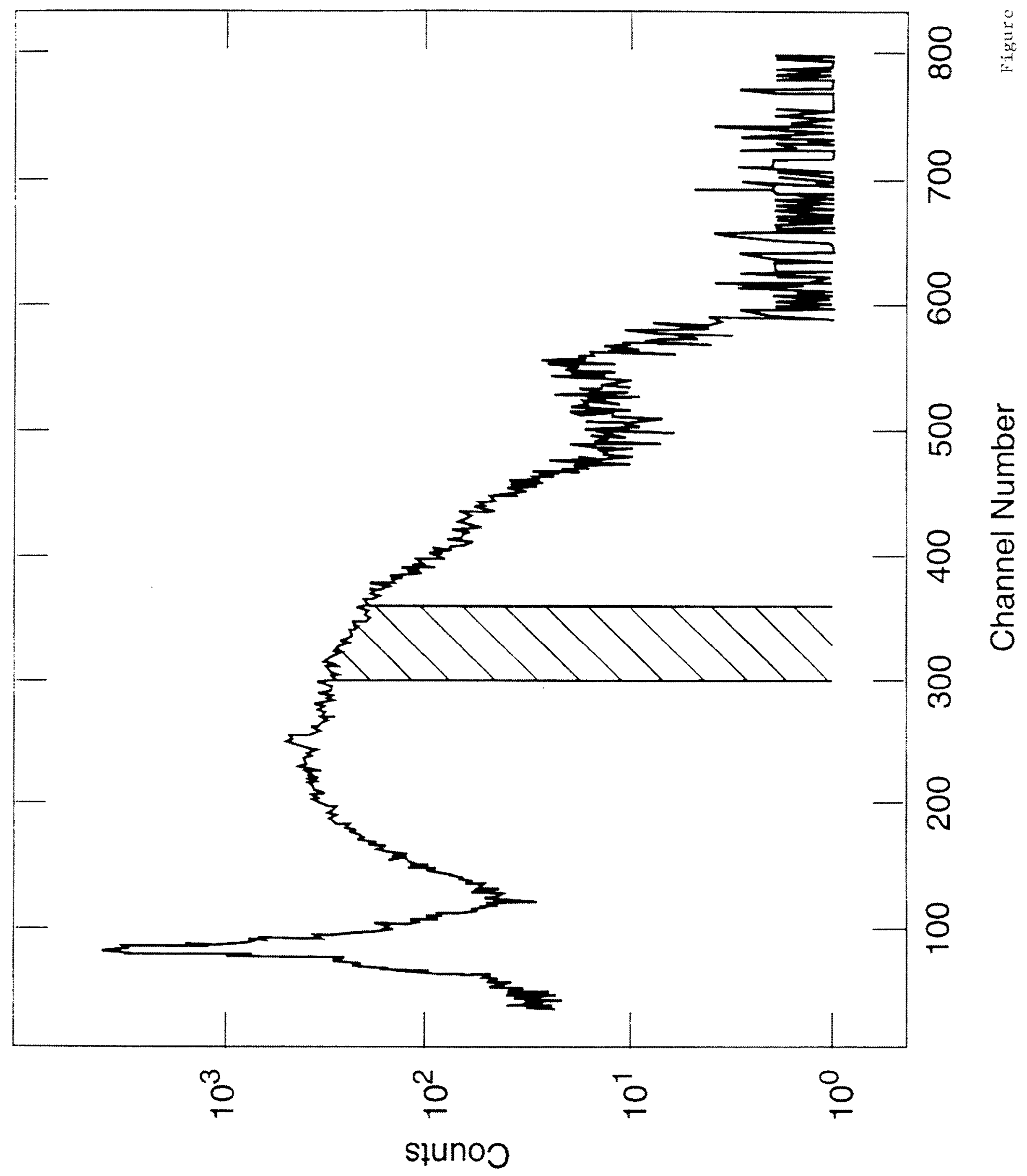




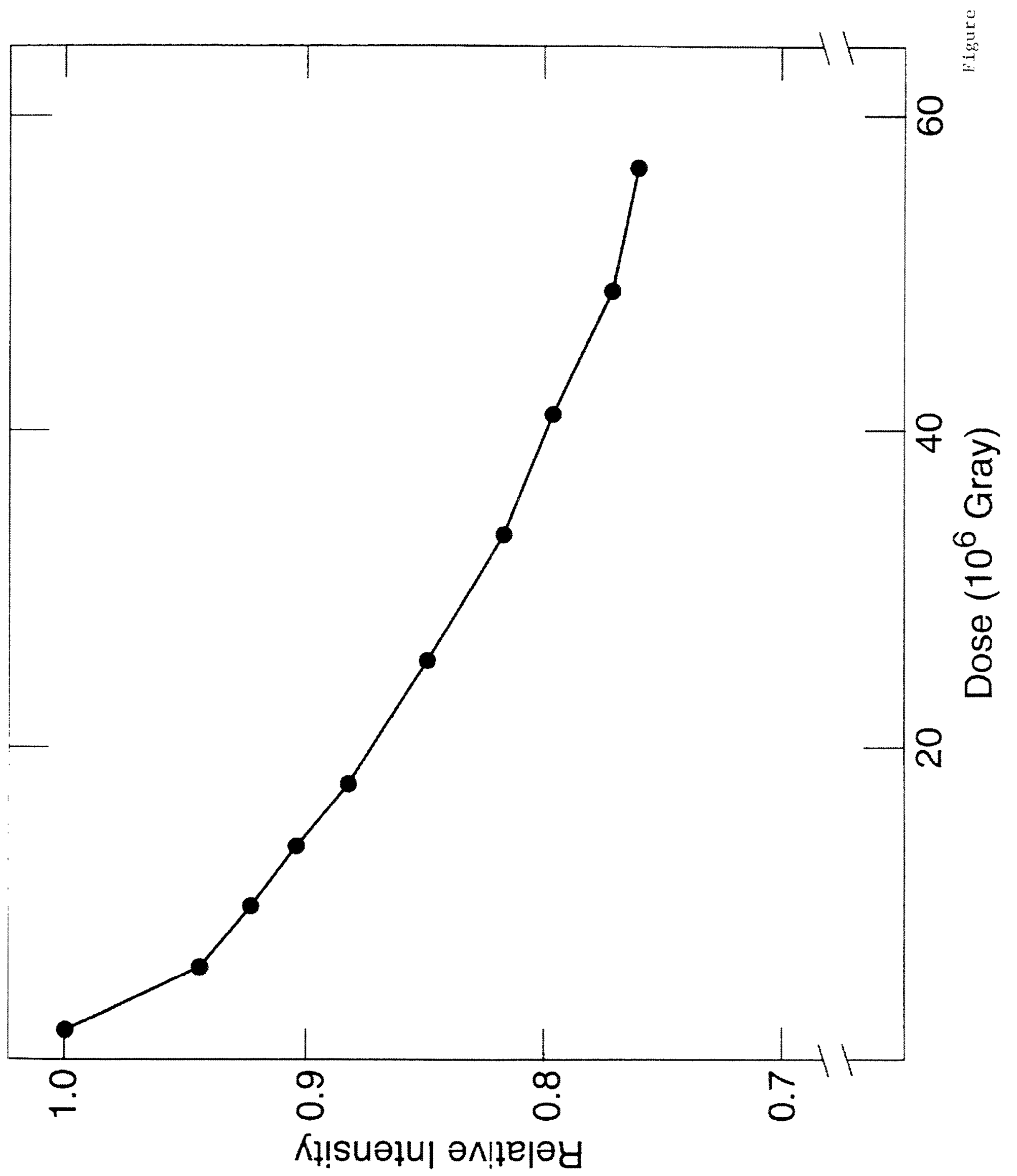



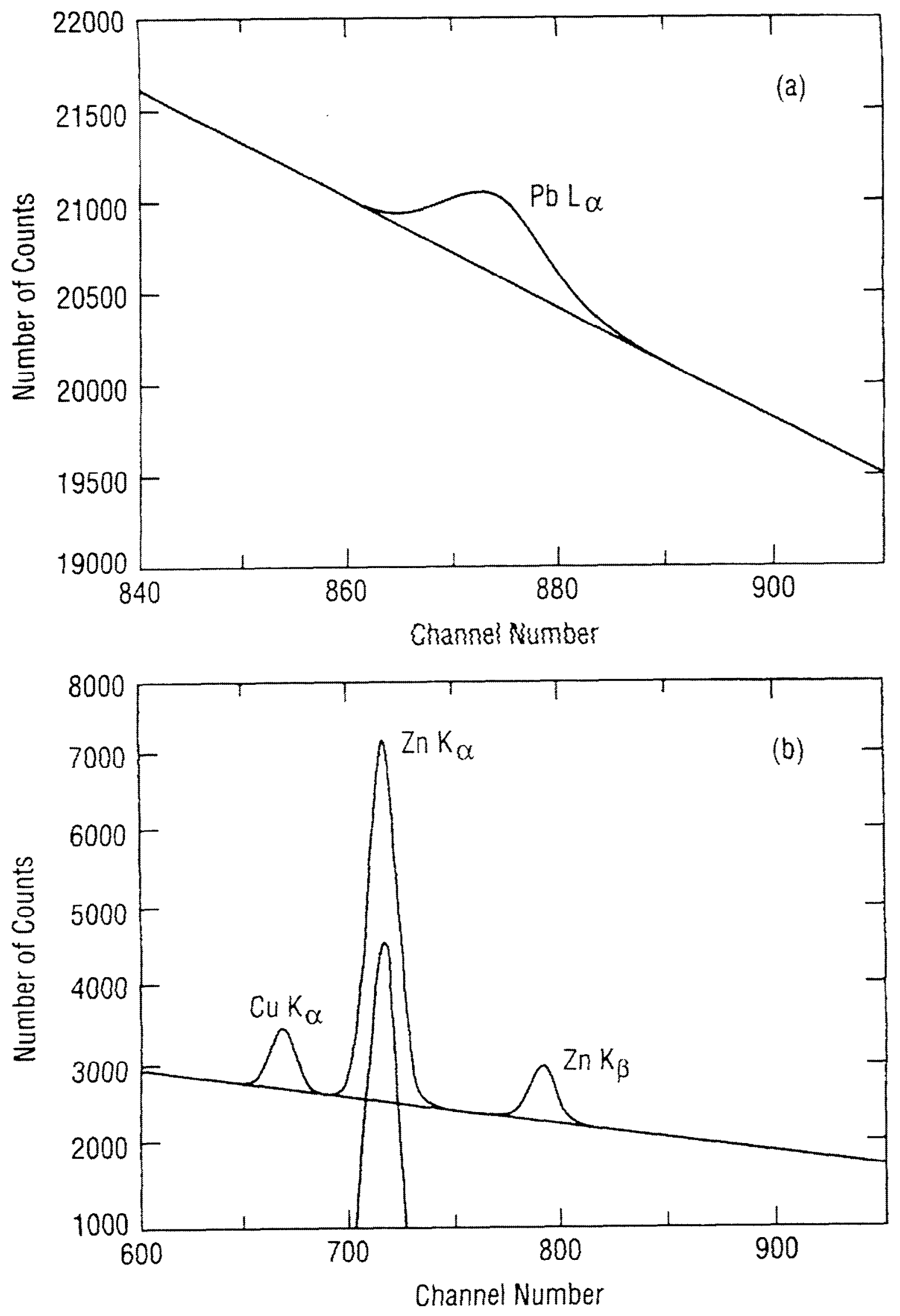

Figure 3.1-1 


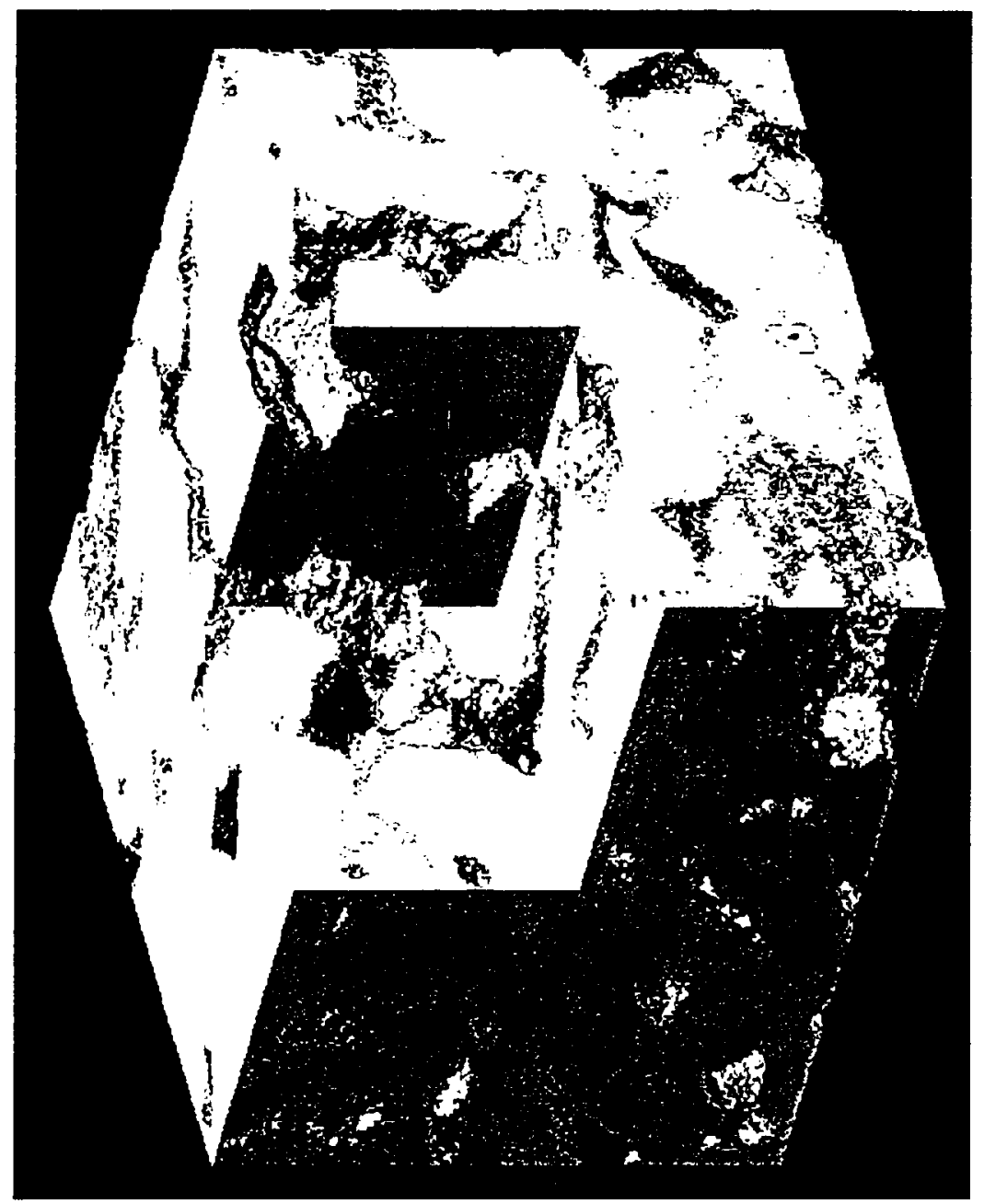




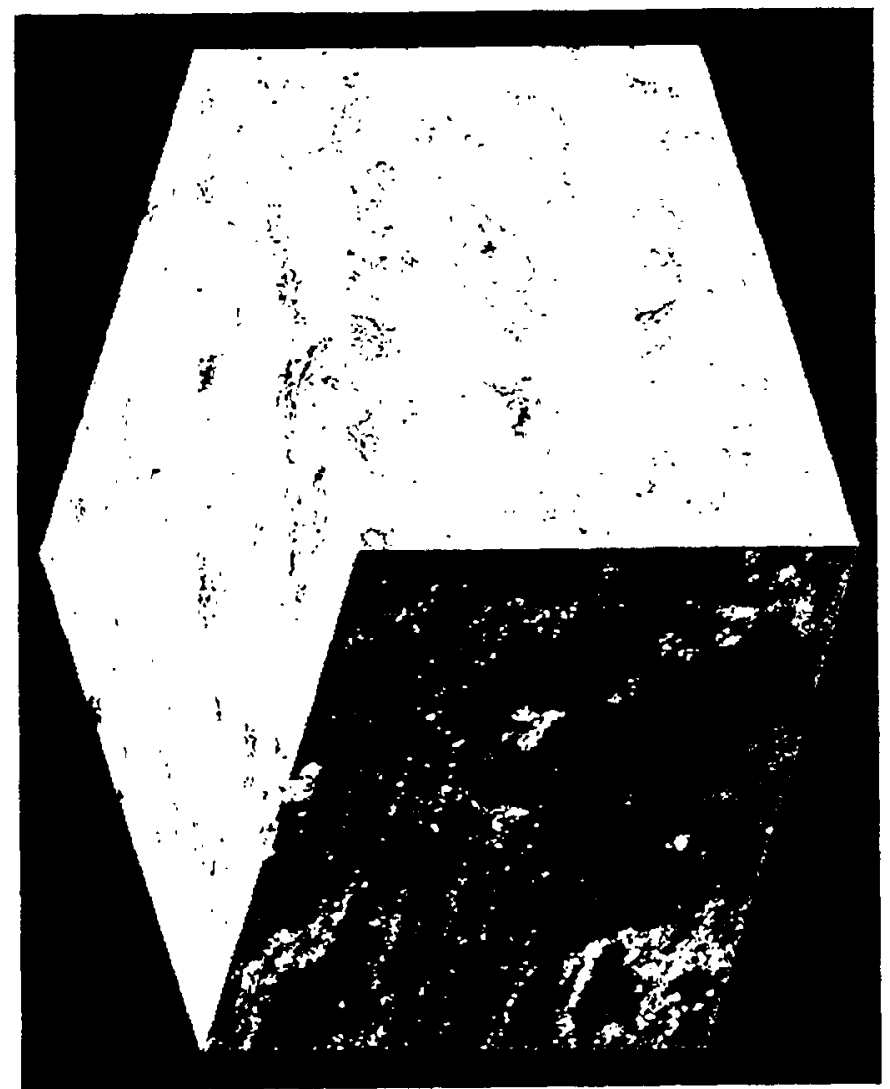




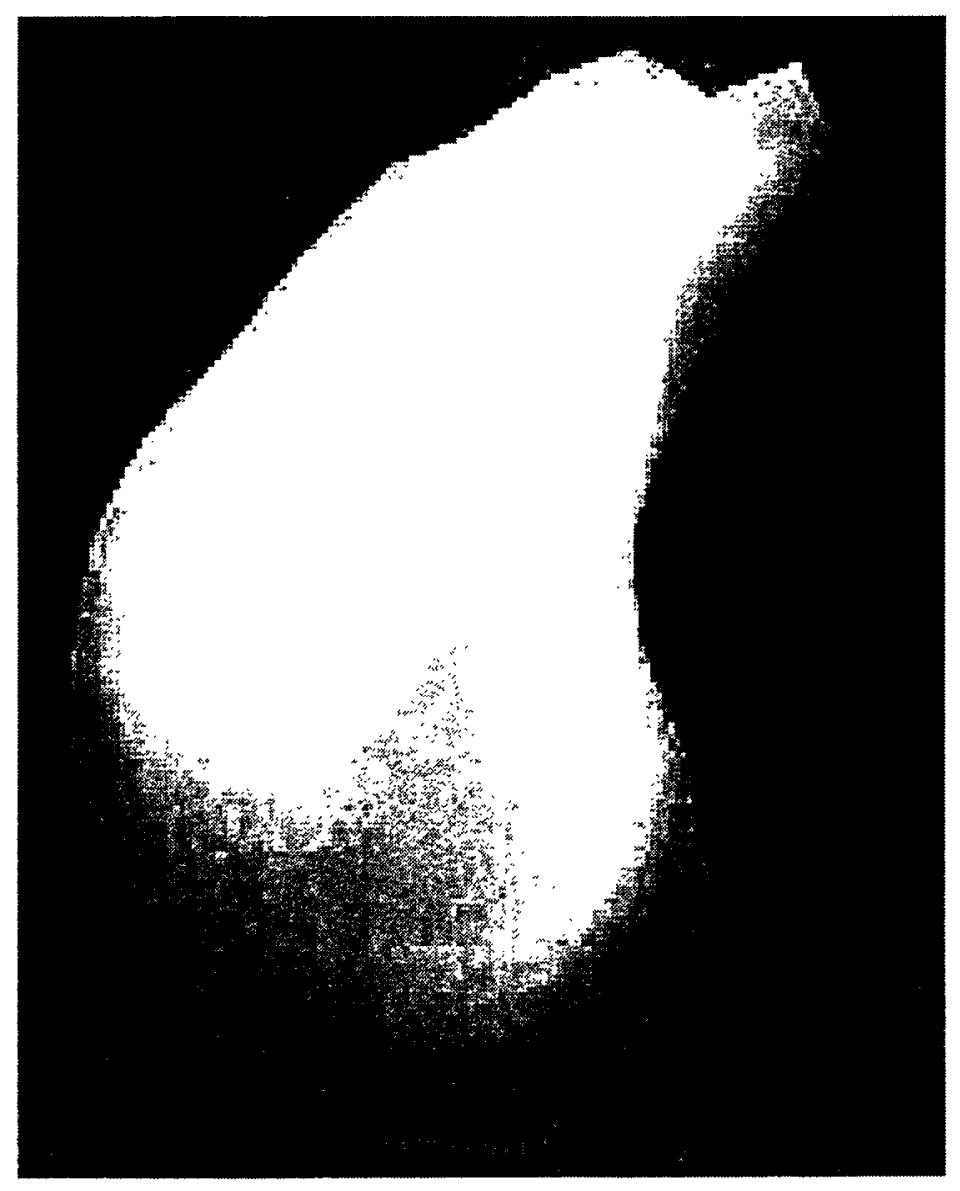




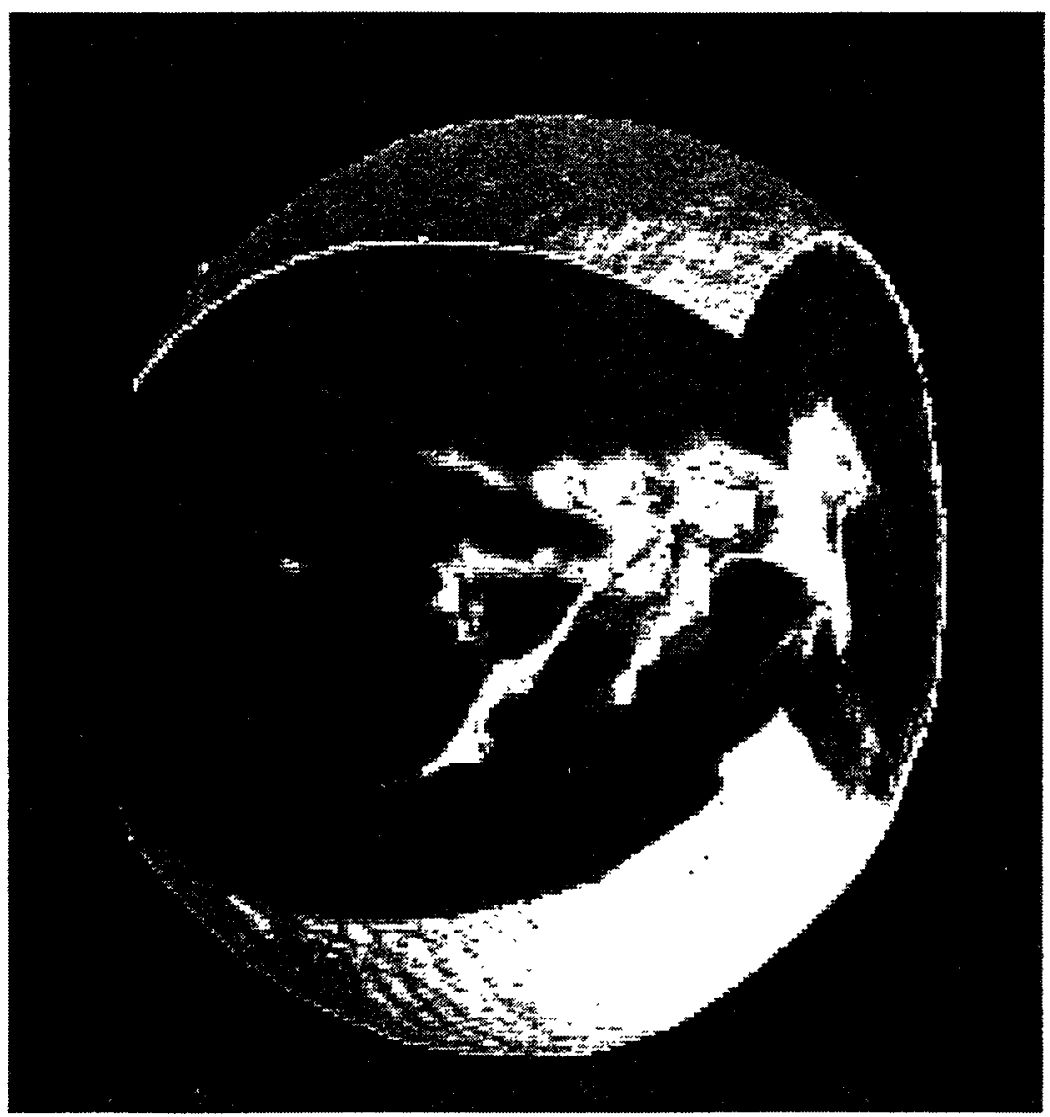

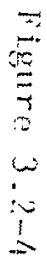




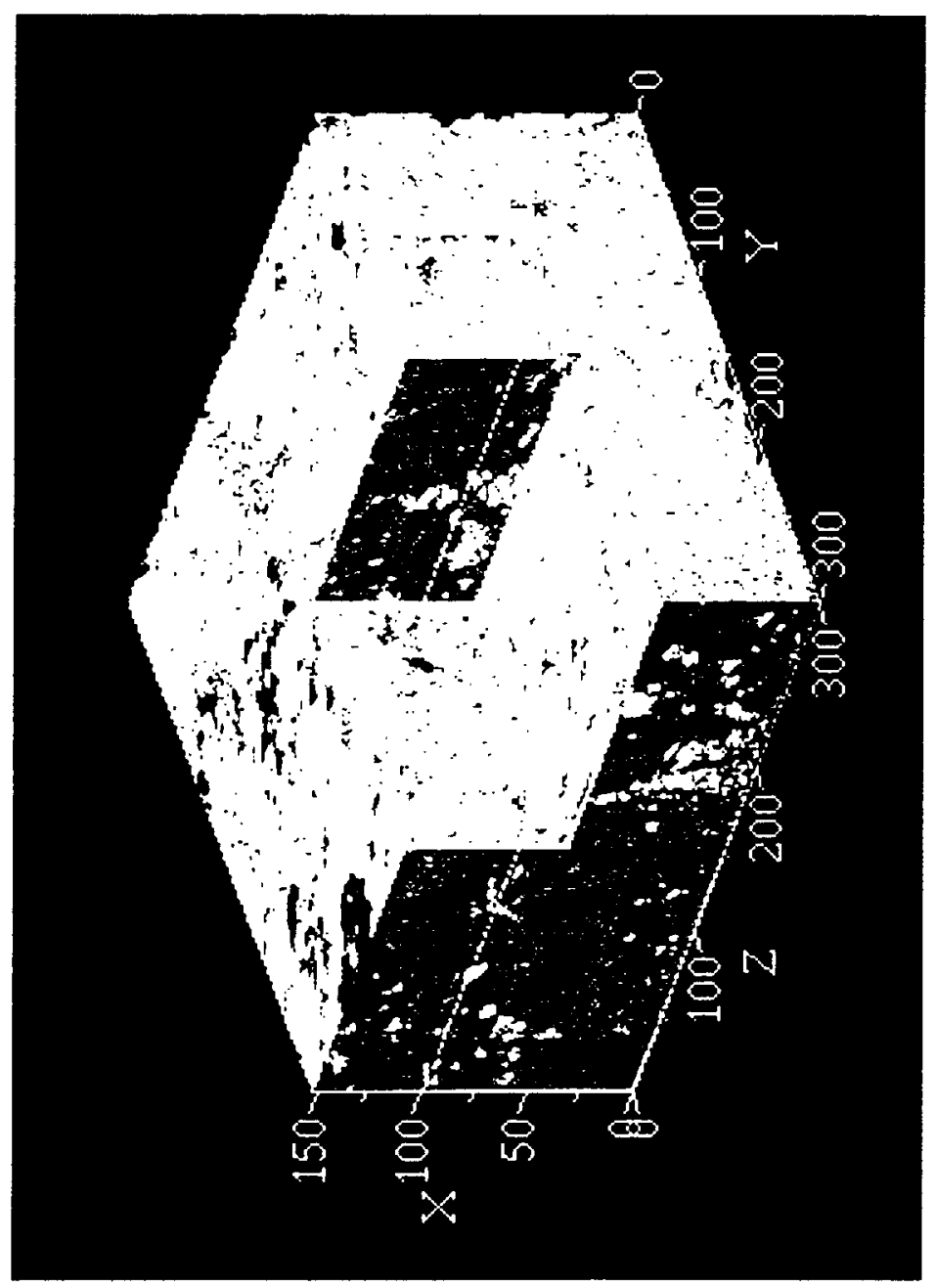




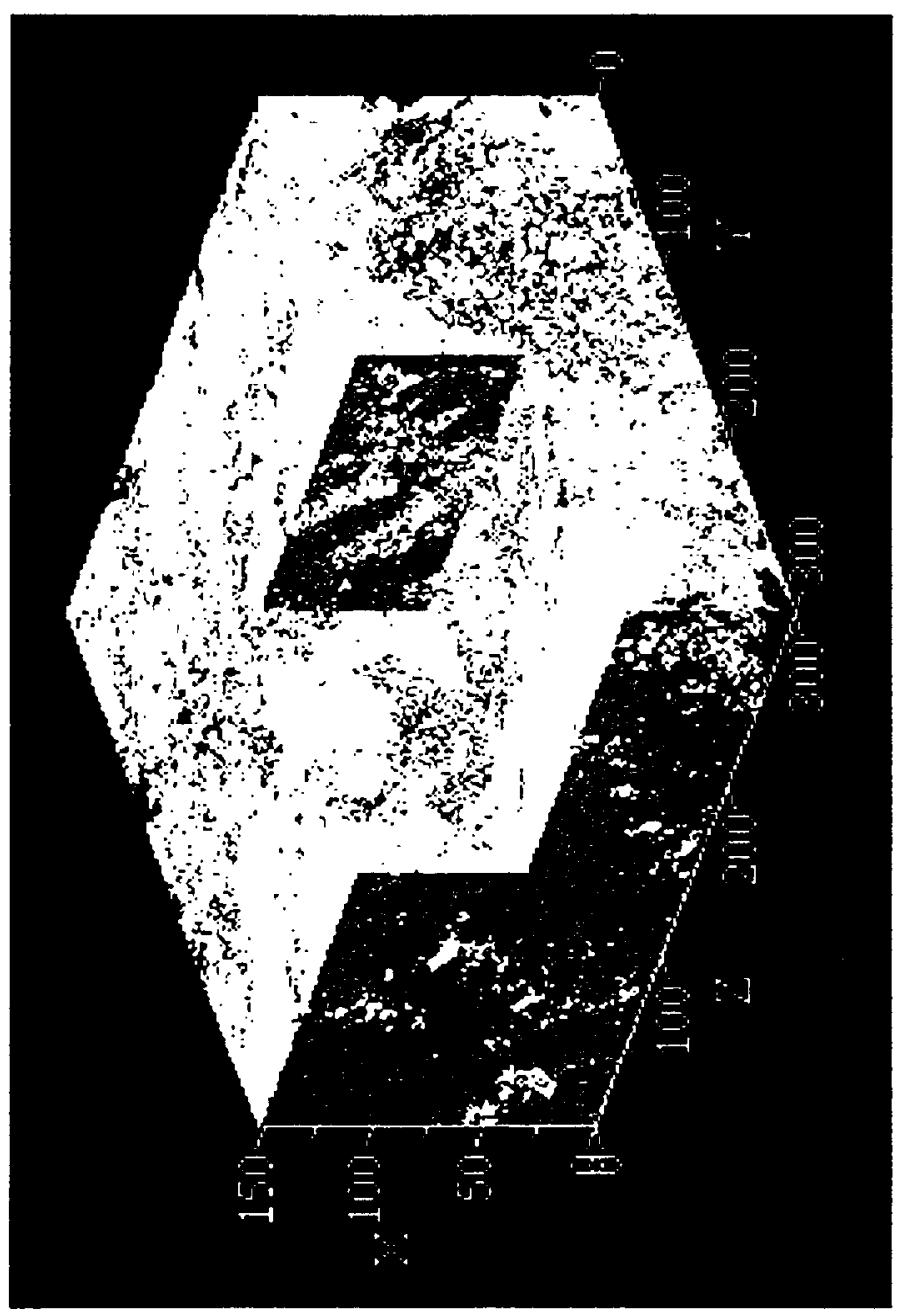




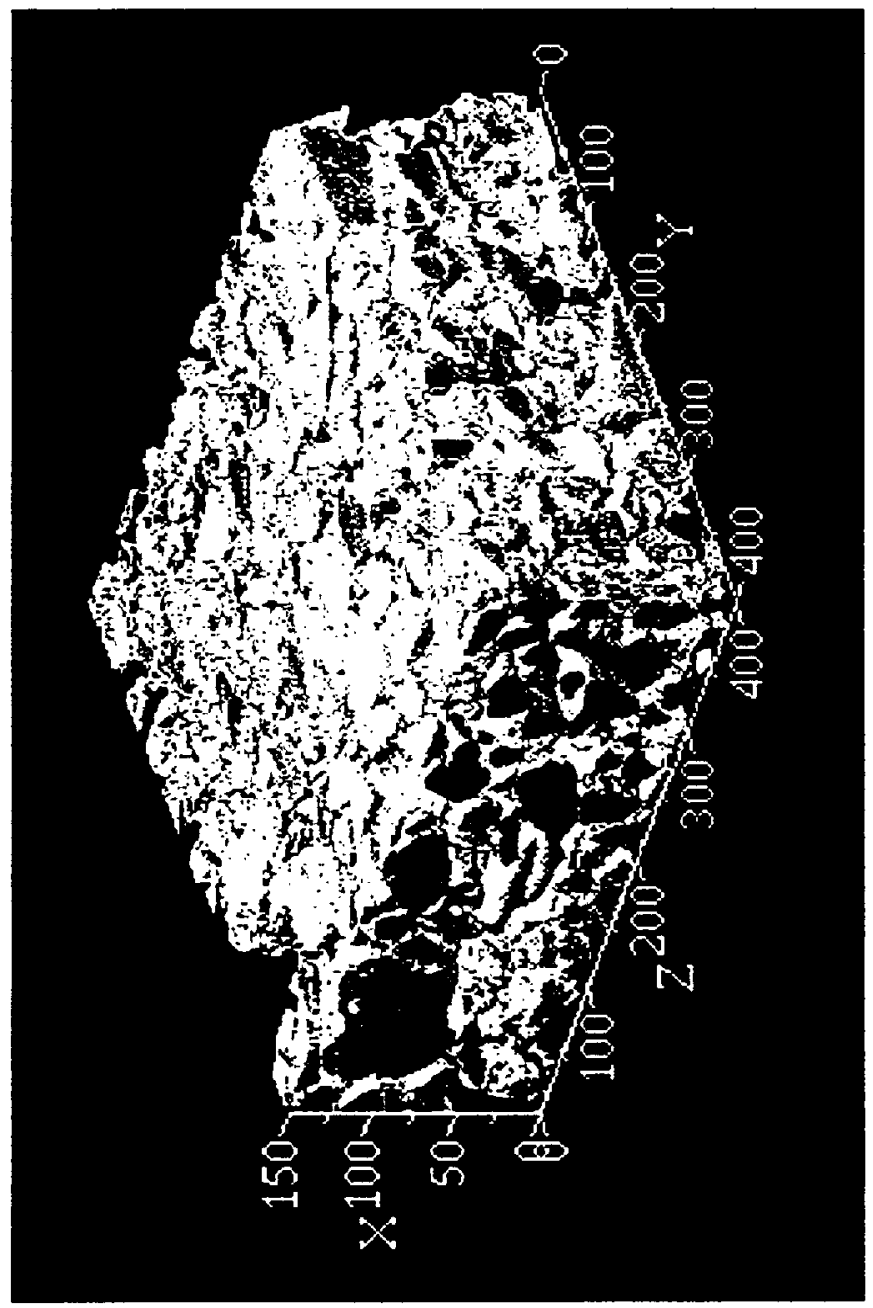



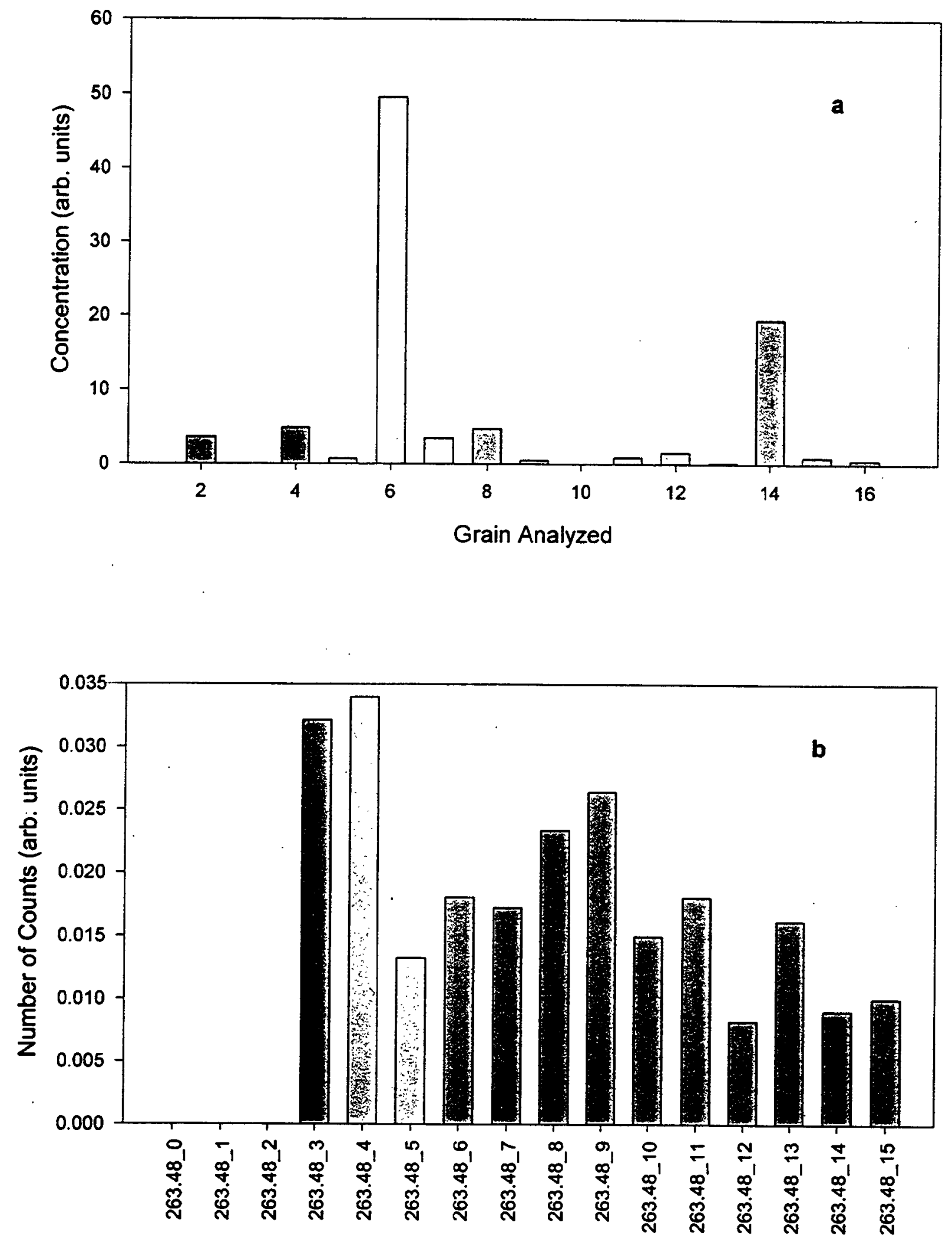

Step Number (arb. units) 

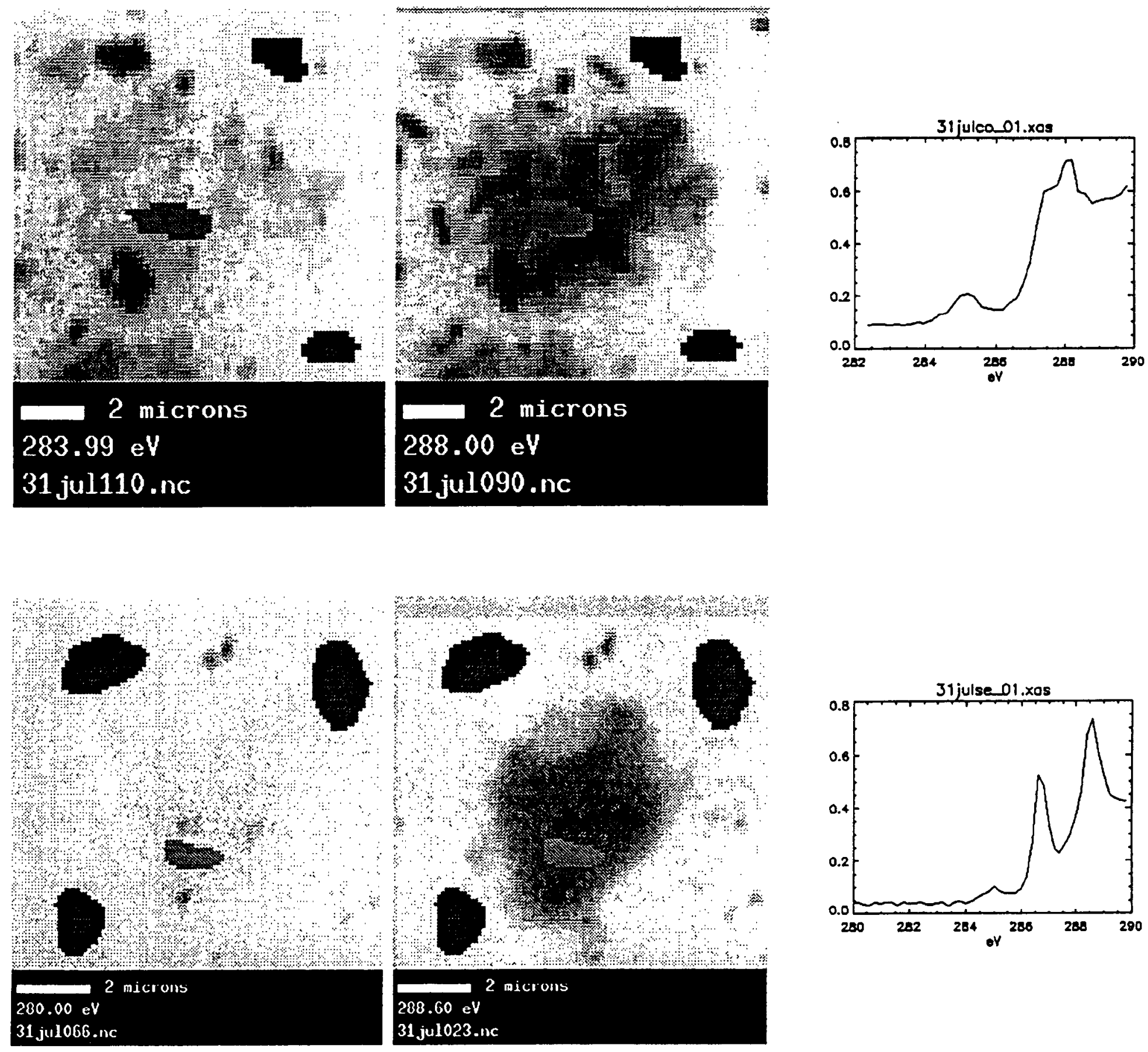
Contaminated Raw Sediments

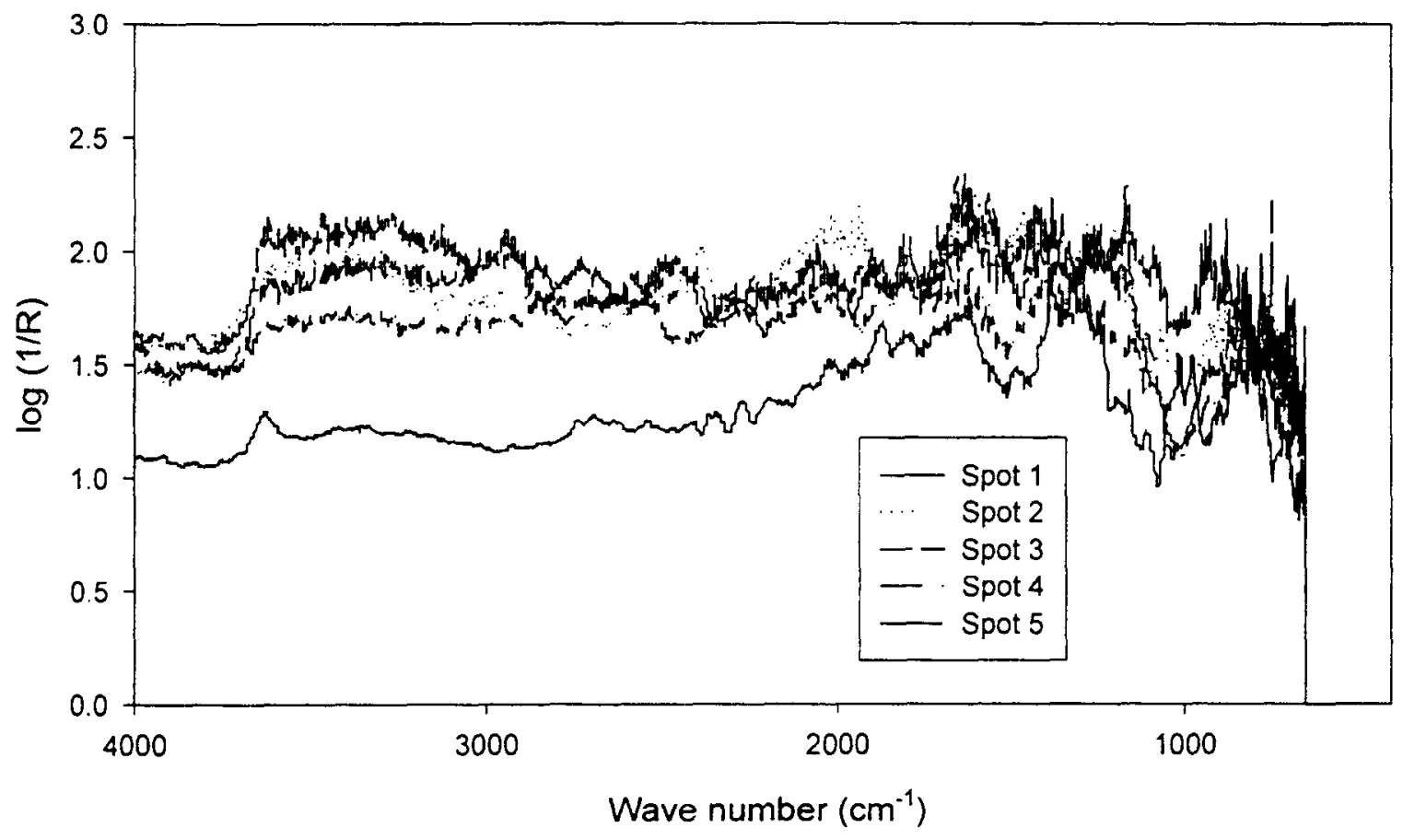

Treated Clean Sediments

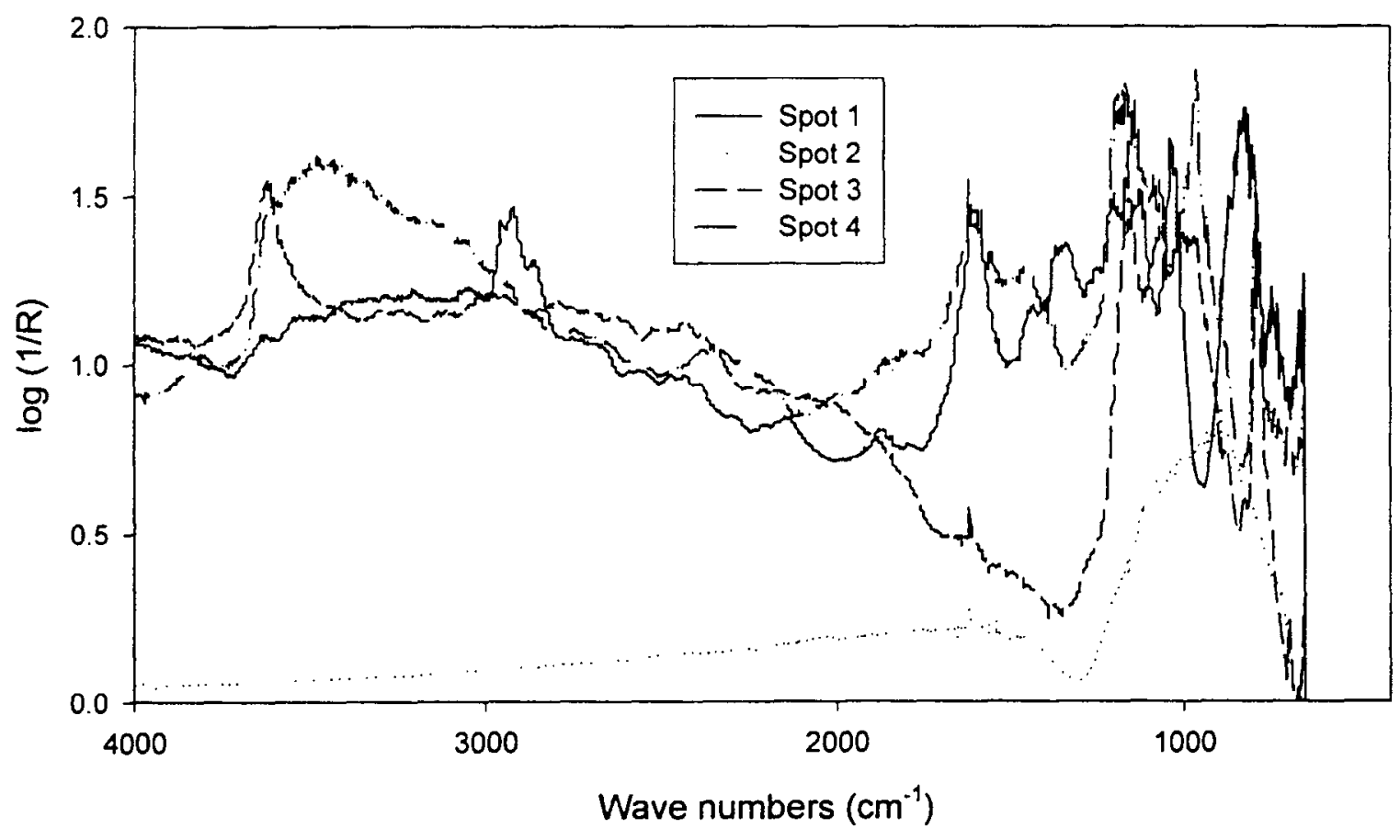

Figure $3.2-10$ 

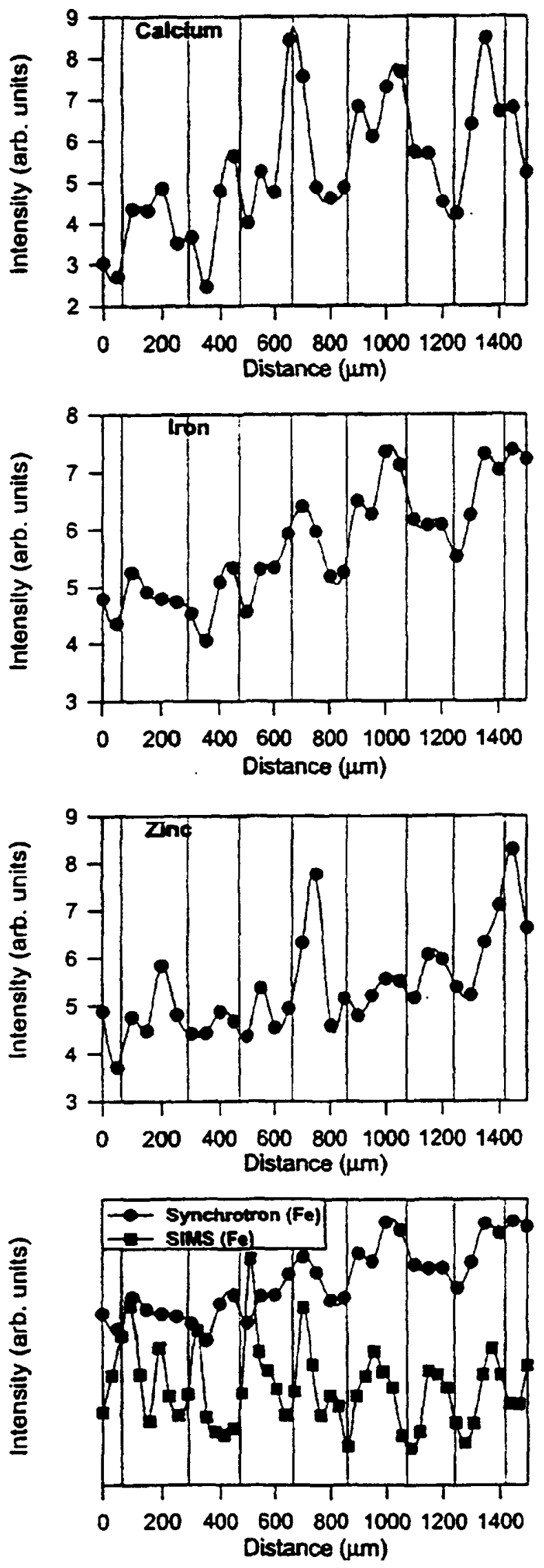

Figure $3 \cdot 3-1$ 


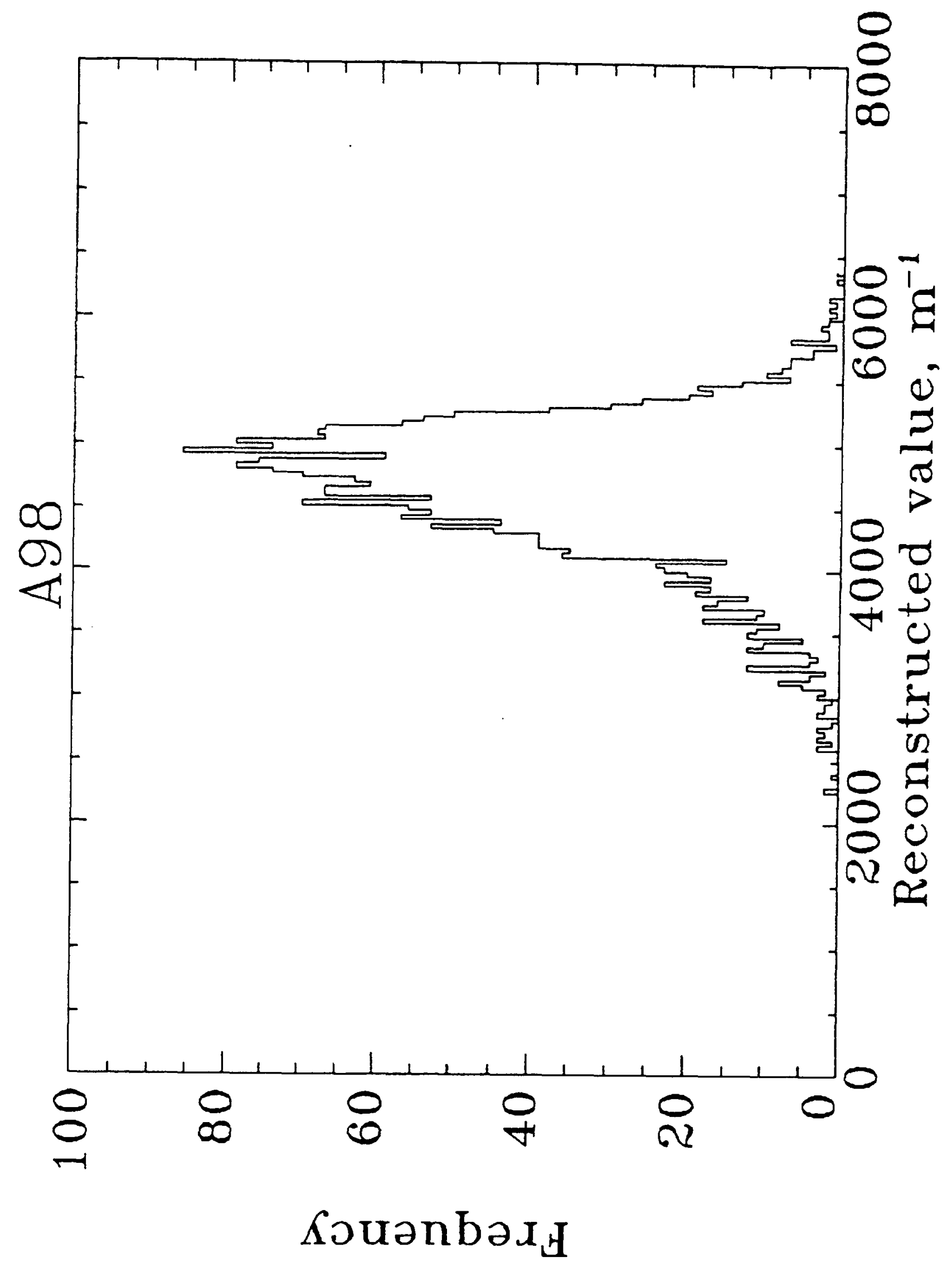




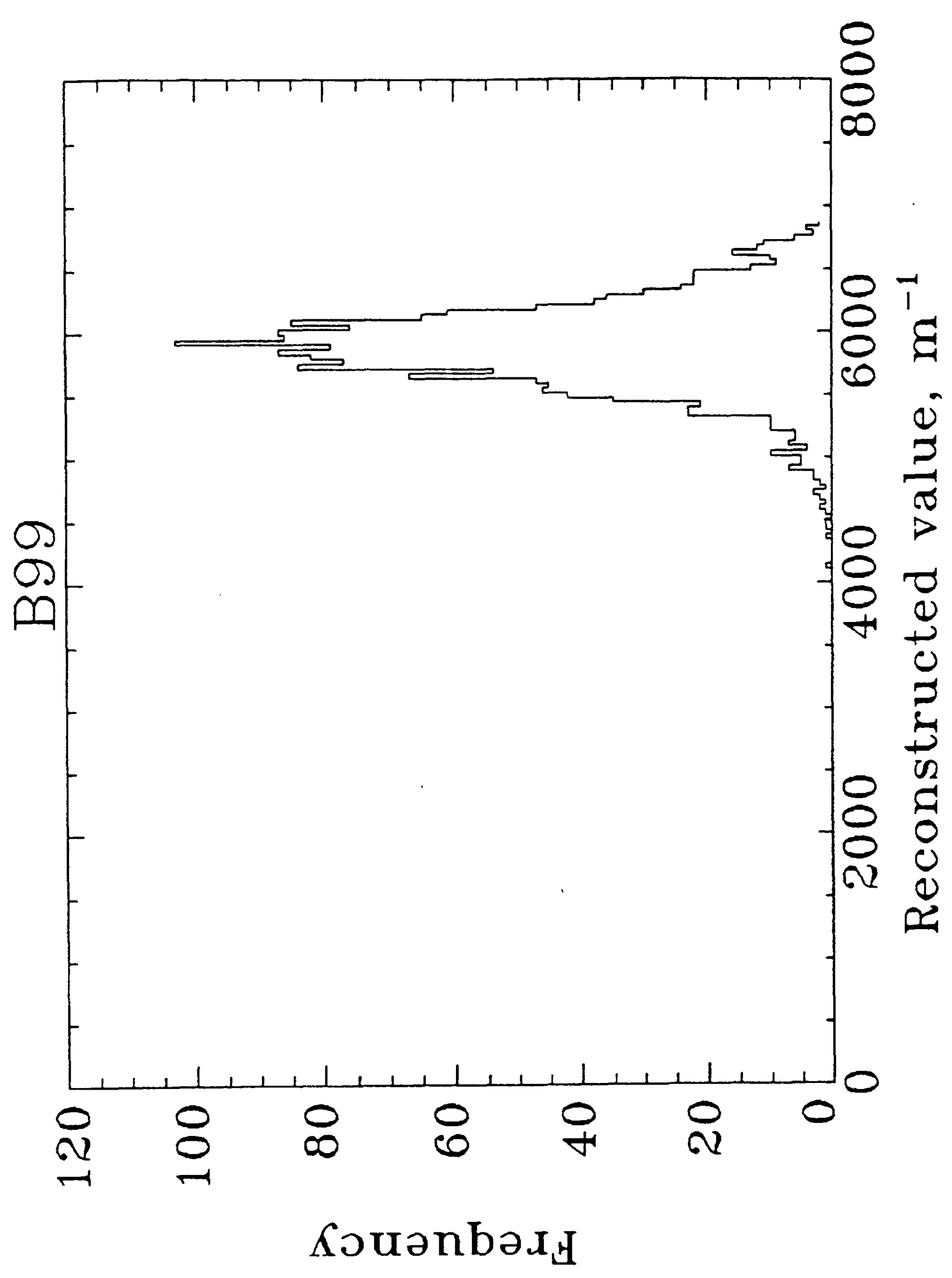

